\title{
Application of IoT in Predictive Health Analysis- A Review of Literature
}

\author{
Geetha Poornima K ${ }^{1,2} \&$ Krishna Prasad K ${ }^{3}$ \\ ${ }^{1}$ Research Scholar, College of Computer Science and Information Science, Srinivas University, \\ Mangalore, India \\ ${ }^{2}$ Assistant Professor, Dept of Computer Science, St Philomena College, Puttur, India \\ ${ }^{3}$ College of Computer Science and Information Science, Srinivas University, Mangalore, India \\ E-mail : poornima.sanjay@gmail.com
}

Area/Section: Information Technology.

Type of the Paper: Review Paper.

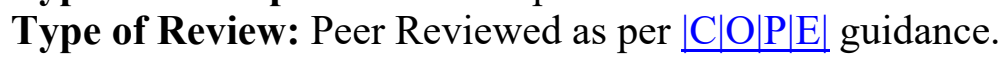

Indexed in: OpenAIRE.

DOI: http://doi.org/10.5281/zenodo.3821147.

Google Scholar Citation: IJMTS.

\section{How to Cite this Paper:}

K., Geetha Poornima \& Krishna Prasad, K. (2020). Application of IoT in Predictive Health Analysis-A Review of Literature. International Journal of Management, Technology, and Social Sciences (IJMTS), 5(1), 185-214. DOI: http://doi.org/10.5281/zenodo.3821147.

International Journal of Management, Technology, and Social Sciences (IJMTS) A Refereed International Journal of Srinivas University, India.

(C) With Authors.

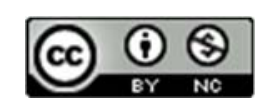

This work is licensed under a Creative Commons Attribution-Non-Commercial 4.0 International License subject to proper citation to the publication source of the work.

Disclaimer: The scholarly papers as reviewed and published by the Srinivas Publications (S.P.), India are the views and opinions of their respective authors and are not the views or opinions of the SP. The SP disclaims of any harm or loss caused due to the published content to any party. 


\title{
Application of IoT in Predictive Health Analysis-A Review of Literature
}

\author{
Geetha Poornima K ${ }^{1,2}$ \& Krishna Prasad $K^{3}$ \\ ${ }^{1}$ Research Scholar, College of Computer Science and Information Science, Srinivas University, \\ Mangalore, India \\ ${ }^{2}$ Assistant Professor, Dept of Computer Science, St Philomena College, Puttur, India \\ ${ }^{3}$ College of Computer Science and Information Science, Srinivas University, Mangalore, India \\ E-mail : poornima.sanjay@gmail.com
}

\begin{abstract}
Internet of Thing (IoT) has influenced several fields these days. Healthcare is one among them. The field of health care has been changed forever with the help of smart devices, wearable along with the overall level of inventions and connectivity in terms of the modern medical equipment. IoT, Cloud computing and other emerging technologies use data from different devices distributed across the network. Among those applications that are facilitated by the IoT, applications related to health care are most significant ones. Predictive analysis is carried out on the real-time data of patients to analyze their current situation for the purpose of effective and accurate clinical-decision making. Generally, internet of thing has been extensively utilized for interconnecting the advanced medical resource as well as for providing effective and smart health care services to the people. In order to monitor the condition of the patient, advanced sensors can be embedded or worn within the patient's body. The data accumulated to such an extent that those data can be examined, aggregated as well as mined to do the initial predictions of diseases. Moreover, physicians are assisted by the processing algorithm for the personalization of treatment and at the same time thereby making the field of heath care more economical. This literature review is carried out by using the secondary data obtained from peer-reviewed journals and other sources on the web. This review aims to explain the use of IoT for providing smart healthcare solutions. The limitation of this study is that the major focus is on application side there by excluding the hardware and theoretical aspects related to the subject.
\end{abstract}

Keywords: Smart devices, Intelligent Healthcare, Sensors, Cloud Computing, EHR, e-Health, mHealth, Telemedicine.

\section{INTRODUCTION :}

Due to the technical advancement the healthcare sector is going through a transformation. Most organizations are extensively using advanced today to reduce costs and expand access to adequate treatment facilities. The healthcare industry has embraced the digital transition and makes it easier for patients and healthcare professionals and adopts the process of delivering healthcare services more streamlined and data-driven. Adopting emerging innovations offers promising opportunities for the health-care sector.
Geographical and time limitations are hindering access to healthcare in both urban and rural areas. In addition to healthcare expenses, acute illness among children and the elderly increases costs associated with transportation. Telemedicine was a step towards progress in the healthcare sector. This program is said to be a very positive effort to bridge the gap between healthcare professionals. The need to minimize the expenses of health care and the sharp increase in the number of elderly patients also happens to be a vital criterion in the emergence of telemedicine services. Personal interaction with a physician, facilities such as medication-related reminders 
from telemedicine providers provided two-way communication between the patients and careproviders. A critical factor in the growth of telemedicine programs often happened because of the need to reduce health care costs and the sharp rise in the number of older patients. Direct interaction with a physician enabled two-way communication between patients and care providers through services such as medicationrelated updates from telemedicine professionals (McConnochie et al., 2006) [1]. Healthcare is a domain where accurate record-keeping and communication is important. E-health evolved out of the need for better recording and monitoring of the health and procedures of patients, particularly for reimbursement purposes, such as by insurance companies. Health care services typically maintained records of their patients' history and status on paper. However, rising costs of health care and advances in technology stimulated the development of electronic monitoring systems (Kart et al. 2007) [2].

The current technology combines real-time data and comprehensive computing-assisted smart health centers that facilitate ambient living. The changes are seen in growing applications such as telemedicine and significant increases in bioinformatics. Wireless sensor networks measure the physiological parameters for instances, blood pressure, oxygen levels, ECG, cholesterol, allergies, and help to address various healthcare issues through potential technologies and devices to treat patients with chronic diseases as well as elderly patients. Information and communication management practices are creating opportunities for healthcare solutions and existing ones. Healthcare IoT-based monitoring systems play a crucial role in the fundamental transformation of healthcare along with the evolution of medicine (Almulhim et al. 2019) [3].

Information technology already has biosensors with sophisticated tools and innovations, ranging from basic paperwork and business purpose software like hospital management information systems to facilitating applications in the healthcare field. Prevention of adoption of renewed technology, economic constraints, and consistency issues are just a few of the obstacles that have slowed the digitalization of the healthcare industry. To overcome these problems, service providers and researchers should not only worry about adopting service, utilities, security, cost-effectiveness, but also a complete evaluation. Also, this study will help to broaden the context of IoT implementation for healthcare and open up new opportunities for healthcare (Al-Turjman \& Baali, 2019) [4].

Economies in developing countries, accessibility to technology, inadequate treatment facilities, caregivers' inadequacy, and medical practitioners are affecting health or care directly or indirectly. Information technology backed by transformation and revolutionary change will overcome all these problems. Health sectors can benefit from information technology such as 1) reducing healthcare costs; 2) uninterrupted access to health information/records; 3 ) remote access to healthcare; 4) Government strategies related to health IT around the world; And 5) improving quality healthcare services (Asghariet al.2019) [5].

End-users, medical professionals, nursing personnel, policy experts, technology experts, researchers, and hardware designers can collaborate to provide effective solutions to healthcare. Numerous autonomous or embedded devices can be interconnected to provide the patients with continuous healthcare. This round the-clock service is especially useful for the elderly people who suffer from chronic diseases. Several clinical tools and technologies are interlinked in the field of healthcare. This concept is known popularly as Internet of Medical Things (IoMT). The basic idea of IoMT is M2M interaction that will take place with the aid of connectivity technologies such as Bluetooth, NFC, ZigBee or Wi-Fi. IoMT can also use Mobile Apps to track patient's heath. Data from wearable devices will be transmitted to physicians offering patients instruction to guarantee continuous monitoring. This decreases unnecessary hospital visits for common illnesses. (Ud Din et al. 2019) [6].

When it comes to healthcare sector, the type of data is used to perform predictive analysis has no limit. Though the data comes from various 
sources, it has to be integrated and analyzed for effective decision-making.

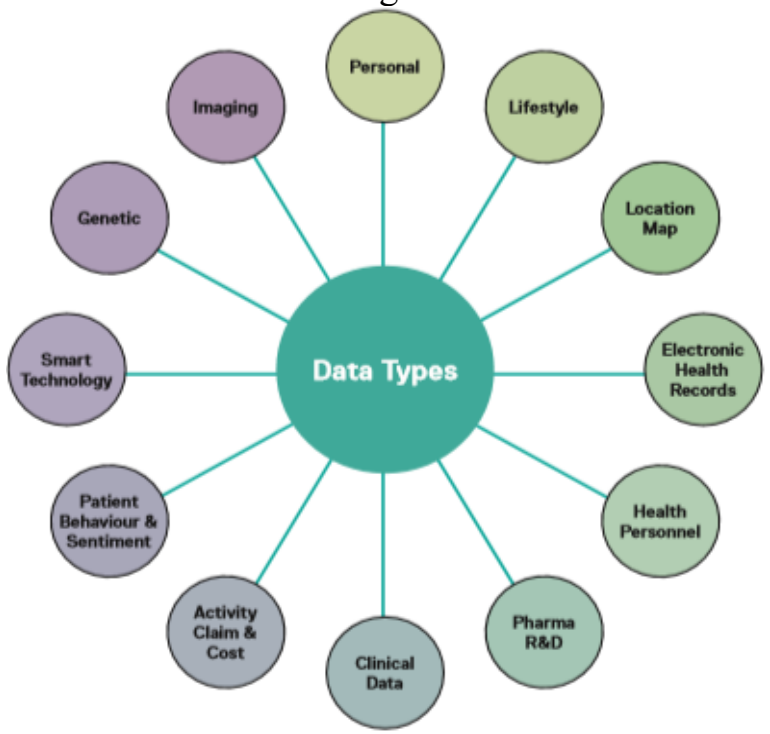

Fig.1: Possible sources of healthcare data (Canada's Big Data Consortium, 2018) [7]

Figure 1 illustrates various sources from which data can be obtained for the healthcare. Personal data includes information such as age, gender, birth date, etc. Smart-watches or smart-phones will easily collect lifestyle data. It includes data concerning day-to-day activities and exercises food habits, etc. Location data may include place of residence, workplace etc. This data is also useful when determining the risks associated with contagious diseases. Healthcare data covers hospital visit records, prescriptions, laboratory reports etc. The EHR data will be available in digital format. Data concerning health personnel are data collected from hospitals, labs, and clinical staff. The pharmaceutical research and development data were collected from pharmaceutical companies' research and development department. It includes information on medications and their use, as well as potential side effects. Medical records contain case sheets stored in hospitals. This data will typically be in the form of files or paper records but will eventually be converted to electronic. Event claim data is linked to medical records maintained by patients for insurance claims. Social and emotional data is that which includes the patients' financial status and emotion-related data. This information will help the doctors determine the reason for the depression. Data regarding smart technology is the one obtained by using IoT tools such as smart lens, smart bands, smart watches, etc. Genetic data is ancestry info. It will be helpful in ChrD's prediction. Image data is that related to X-ray images, MRI scans, US scans, PET scans, etc. (Big Data Consortium of Canada, 2018)[7].Using IoT, a virtual framework is built that links healthcare providers, patients, families, and the government. The new service helps patients and doctors to make better choices by keeping patients at the forefront of the program (Son et al. 2017) [8].

The process has a lot of challenges to it. Ensuring privacy and security to patient data providing connectivity round the clock, selecting the appropriate algorithm to provide reliable results and information overload are a few among them (Caban et al. 2015) [9]. This literature review paper tries to shed light upon (1) IoT Based Intelligent Healthcare System, (2) Architecture of Intelligent Healthcare System, (3) Approaches for IoT based health status prediction,(5)Use cases of IoT application in Healthcare, (6) IoT personalized healthcare devices, (7) Future of IoT in healthcare, (8) Research gap, (9) Research Agenda, and (10) Conclusion.

\section{OVERVIEW OF PREDICTIVE HEALTH ANALYTICS :}

Almost 50 percent of the total population about 40 years of age suffers from one or the other chronic illness. Chronic diseases are the world's main cause of death. The cure of chronic diseases requires significant amount an individual's savings (Yach et al. 2015) [10]. Technological progress has created a major breakthrough for the healthcare industry. The power of data analysis and advanced technologies would work well for patients with chronic ailments. The current situation and development of the disease can be accurately measured based on data from electronic health records (EHRs) and clinical data of patients (Cohen et al.2014) [11].

Prediction and prevention go hand in hand. If the future condition can be anticipated earlier, further progress of the disease can be easily avoided thus mitigating the potential damage in the near future. This is of great benefit to patients suffering from 
diabetes and cardiopulmonary disease. The inevitable re-admissions to hospitals can be reduced if the patient is monitored continuously. This ensures continuous care for the patients. The basic idea of using IoT in healthcare sector is to doctors spend more time with their patients instead of reading their Personal Health Records (PHRs). This provides better care, at reduced healthcare cost. (Parikh et al. 2016) [12].

\section{RESEARCH GOAL AND METHOD} OLOGY :

The approach used in this study is a qualitative one that focuses mainly on the theoretical model applying predictive analysis in healthcare. The core aim of this study is to gain insight into the situations that include implementing IoT in healthcare, the advantages of integrating multiple devices and different individuals, and the related challenges. Besides this, the purpose of the study is to provide a scenario for new research prospects. The following questions are beneficial to achieve desired goal:

- What is the influence of IoT in developing intelligent healthcare solutions?

- What are different approaches for predicting the health status using IoT?

- What are the IoT devices and applications used in smart healthcare?

- What are the fields of healthcare that use IoT solutions extensively?

- What are the emerging technologies used for developing smart healthcare solution?

In addition, we have proposed a few research gaps based on the analysis, which are described in the section 6 .

\section{LITERATURE REVIEW :}

IoT is an emerging technology with the help of which 'people' and 'things' are connected 'anytime', 'any place' with 'anything' and 'anyone'. The new technology will make the dayto-day life of an individual easier, simpler and better (Caban et al. 2015) [9].

One of the most popular and prevalent fields that uses IoT is the healthcare sector. It aims to provide 24/7 aim to track the vital sign of patents, eliminating the patient's need for hospitalization. Before the emergence of IoT, also through e-health (electronic health) this was implemented. But between sensors and remote servers through traditional 'telehealth' treatment applications in the traditional health-care application two-way communication among sensor as well as the distant server that is quite impossible. In addition, Gateway or remote servers cannot communicate directly with the sensor node. Furthermore, IoT is made it possible by using current Internet protocols for example IPv6 that detect various sensors and devices directly through the Internet, together with environmental monitoring sensor. It tends to be difficult for patients and costly (Babu et al., 2013) [13].

There are two approaches for identifying and protecting the health status of the patients either without or with an activity recognition method. Along with that, non-activity-based recognition method can be also divided into two groups, such as the traditional method and the IoT-based method. In the context of the conventional method, the patient's health data is stored in a variety of learning methods and further analyzed to determine the most contributing source of the patient's diseases. Besides, it is done using the learning methods, for example fuzzy logic or ANN (Azar et al., 2019) [14].

Following are some of the major weaknesses of the conventional healthcare system

- It follows a totally disconnected architecture where there is no or limited connection between a medical practitioner and patient

- The collection and storing of voluminous data. In fact, the data is heterogeneous.

- The application is not patient/user-centric and is therefore not customized

The reasons for using IoT in healthcare include

- Voluminous heterogeneous data can be effectively stored on cloud.

- A wide variety of applications are available that can efficiently analyze data and forecast disease progress

- Patient-physician engagement will increase, as smart devices send data on a regular basis. Therefore, doctor knows the patient's exact condition. This ensures better care (Jeong et al. 2014) [15]. 


\subsection{IoT BASED INTELLIGENT HEALTHCARE SYSTEM}

Smart healthcare is defined as "adopting information communication technology (ICT) for the amelioration of health through prevention, examination and treatment of physical/mental illness, injury or disorder". The smart healthcare system includes smart instruments, on-body sensors, laboratory technicians, physicians, healthcare personnel, smart emergency response system, etc., connected with IoT's support. IoT is widely used to lighten the burden of the hospital system, to improve healthcare quality and to reduce overall healthcare costs. (Chui et al. 2017) [16].

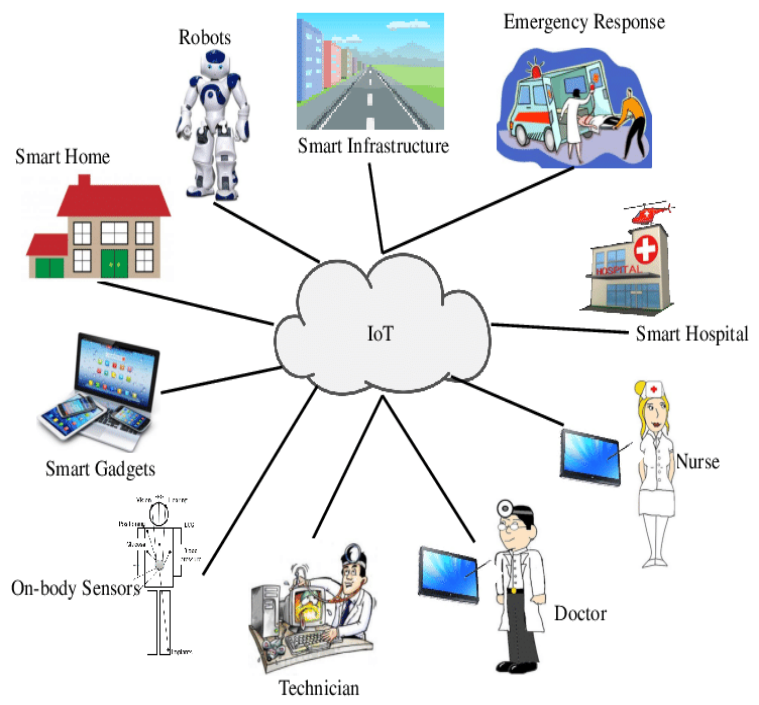

Fig. 2: IoT Based Smart Healthcare

Source:

https://www.researchgate.net/figure/The-IoT-isthe-Backbone-of-Smart-Healthcare/

Figure-2 shows numerous entities that can be connected to form an intelligent-healthcare system. It includes sensing devices mounted on the patient's body, smart gadgets used to send information, smart home equipped with sensing devices, robots that support doctors perform specialized operations, smart infrastructure, smart ambulance network, smart hospitals, clinical staff and connected laboratory technicians use IoT platform to provide efficient healthcare.

In remote healthcare management systems, IoT is becoming increasingly prevalent where 'things' interact and collaborate among themselves to promote decision making. The smart objects used in IoT are easily prone to malicious attacks and are very much sensitive. Protecting and preserving smart things, allowing omnipresent networking and complex overhead in computation to be potential issues, the healthcare sector is the prominent one that attracts researchers to a large extent. To ensure security of IoT systems a model using Body Sensor Network (BSN) was designed and demonstrated (Yeh 2016) [17].

\subsection{ARCHITECTURE OF INTELLIGENT HEALTHCARE SYSTEM}

Because of the increasing popularity of IoT and widened research opportunities several architectural frameworks have been proposed for the implementation of eHealth. The diagram bellow shows the layered architecture of IoT based intelligent healthcare system.

Several technologies such as communication technology, sensor networks, data processing, cloud computing, and data visualization should be integrated to incorporate IoT related applications. Figure 3 shows the layered architecture of IoT systems used in healthcare. It contains five lavers namely sensing, sending, processing, storing and mining.

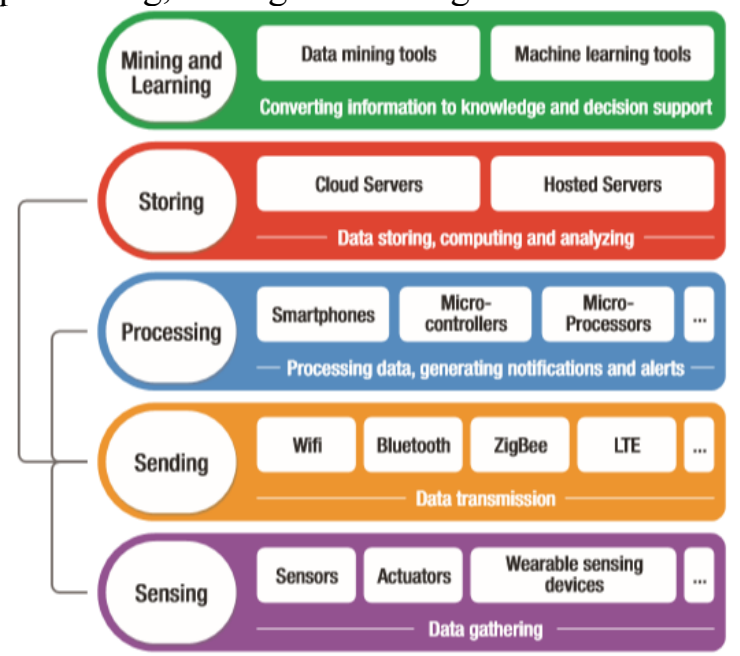

Fig. 3: Layered Architecture for IoT (Ud Din et al. 2019) [6] 
- Sensing: This layer comprises sensors or wearable devices that are used to capture parameters such as body temperature, blood pressure, heart rate, respiration rate etc. While designing this layer, cost and energy consumption capability of the sensing devices are the important aspects to be considered.

- Sending: This layer contains several devices and protocols required to link 'things' for data sharing reason. Bluetooth, ZigBee, NFC, WiFi are a few examples of technology used for connectivity. The Device management, energy consumption, protection and privacy are some of the points to remember when designing this layer.

- Processing: This layer contains the processing units and the software required to aggregate the data.

- Storing: Physical objects produce voluminous data that is to be processed for decision-making purposes. There are several cloud services available to efficiently store the data.

- Mining and Learning: This layer converts information stored on the cloud into valuable knowledge that is much needed for decision taking purposes (Ud Din et al. 2019) [6]

\subsection{APPROACHES FOR IOT BASED HEALTH STATUS PREDICTION}

Baig et al. (2019) [18] applied multiple classifiers along with a decision tree, rule-based methodology, artificial neural network, and Naive Bays to a large dataset of clinical resources with substantial heart attack attributes to forecast the falls and activity of daily life (ADL) of elderly people. They demonstrated that the Naive Bayes approach beats different strategies. Their model is able predict the health status for every customer, in view of the spatial and temporal data of the patient. The authors confirmed that wearable tools were used to predict irregular behaviour. According to them, the key things to consider when developing IoT applications for healthcare are user-acceptability, user understanding, clinician and patient acceptance. Within a fixed location, devices such as heart monitors are 'constrained'. This makes the application less versatile. Most of the sensors generate data that contains noise. According to them, extraction of valid data and providing batter support to the smart devices are of greater challenges in the IoT enabled healthcare systems. Bhawiyuga et al. (2019) [19], suggested a framework for identifying irregular circumstances at home that are especially appropriate for the elderly and those who live alone. The use of various wearable devices and sensors gathers qualitative data such as temperature, blood pressure, pulse rate, etc. According to them, device heterogeneity and diversity of applications including a web server or mobile app, or any other service that uses data needs a middle-ware. To provide much needed inter-operability the middle-ware is required. The middleware developed is named as WoT (Web of Things), which uses Restful HTTP for the user's non-real-time data and MQTT for the real-time data.

Boulos et al. (2019) [20] proposed a system that uses sensors to gather patient real-world data along with current location of the patient. It integrates artificial intelligence and geographical information of a patient to provide customized healthcare solutions using IoT. This is called as GeoAI based healthcare solution. Analysis of certain diseases not only requires qualitative data such as ECG readings but also require the data related to location, lifestyle and social behaviour of the patients. Along with "what", the GeoAI system uses a "where" component to optimize the solution. Clustering techniques, machine learning etc are helpful in the analysis of location-specific data. The geographic information can be helpful in assessing risk factors for a disease and identifying potential preventive measures. For example, those living in heavily polluted areas are suffering from asthma or some breathing problems.

According to Parikh et al. (2016) [12], a term called "Precision medicine" or "Precision delivery" is becoming popular with increased use of real-time clinical data produced using EHRs. "Precision medicine" integrates data from EHR as well as machine learning techniques to provide the patients with customized treatments. This idea is useful for providing the necessary postdischarge services to patients who are suffering 
from chronic diseases or who are resting after a major operation. This in turn reduces the number of re-admissions to hospital. Physicians and healthcare professionals can access the real-time data from EHRs and provide necessary consultation over the phone or with the help of mobile apps.

Lin et al. (2017) [21] proposed the Bayesian Multitask Method to Learn (BMTL). In this method, multiple interrelated tasks are evaluated together, rather than getting explored separately. It is important for those diagnosed with multiplerisk chronic diseases such as diabetes. The idea accelerates the process of diagnosis by taking into account several risks associated with the patients. In diabetic patients the concept is useful for predicting. Diabetes has three adverse effects on the body, including stroke, heart attack and renal failure. Rather than of evaluating the symptoms of these three risks individually, they are collectively analyzed to produce fast, reliable results.

Wu et al. (2017) [22] proposed Wireless Body Area Network (WBAN) technique. They recommend a flexible mechanism for energy harvesting which uses solar harvesters to supply power to the wearable devices. The wearable sensor nodes contain a micro controller unit (MCU) for measuring qualitative data. Multiple sensors are installed on the patient body to measure temperature, pulse rate, blood pressure etc. With the assistance of a smartphone, the data from these sensor nodes is transmitted to the cloud. It is then processed and, in the case of an emergency, alert notifications will be transmitted without human intervention to doctors, patient family members and emergency services, such as ambulance.

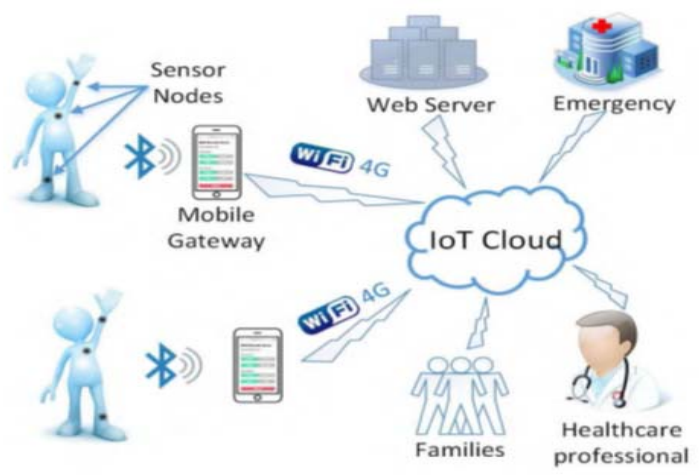

Fig. 4: Wireless Body Area Network with IoT connected healthcare (Wu et al. (2017) [22].

The WBAN network, as shown in Figure-4, links many health service stakeholders with the aid of the Internet. With the support of smart-phones, sensor data is collected and sent to the cloud platform. All actors in the health care system may use these data to provide effective healthcare.

There is a heterogeneous nature for clinical data. Advancements in electronic technology have resulted in the invention of advanced instruments used to capture precise clinical data. The devices generate various output types like images, ECG readings and some quantitative data like temperature. Different techniques such as AI, machine learning, artificial neural networks, etc are required to process the heterogeneous data. The incorporation of heterogeneous instruments and heterogeneous techniques will provide better and reliable performance. (Knickerbocker et al. 2018) [23]

According to Kodaliet al. (2016) [24] most hospitals do not structurally store patient data. That requires additional financial overhead if it is to be processed in an organized manner. In healthcare the use of IoT devices makes the system more transparent. IoT establishes digital identity for every patient and stores their data in a data center. Often cloud computing can be used to make the data more pervasive. The paper also proposes a model for the provision of healthcare services. It can be seen as a sophisticated model when combined with Internet and Cloud platform. Adopting IoT in healthcare is a simple task in India, as there well-qualified medical professionals who can easily use the technology with limited or less training to use it.

In Joyia et al. (2017)'s opinion [25], IoT has brought rapid improvements to the healthcare sector. Managing complexity, scalability and ensuring round the clock connectivity being key challenges, IoT is being used extensively in healthcare. This is used mainly to identify the disease at an earlier stage to prevent potential damage and to provide patients with precise solutions. Because of the interconnected things, hospitals are transformed into 'smart hospitals'. Smart devices will detect significant differences in patient data along with appropriate support of specific applications, and deliver alert messages 
to various stakeholders. The 'Smart Apps' used in IoT are easy and simple to use.

Gandhi et al (2017) [26] provide insight into how innovations and opportunities in the healthcare sector have changed from doctor-centered to patient-centered, from healthcare to telehealth, eHealth, mHealth and finally 'intelligent' healthcare. The authors also provide architectural framework along with the protocol stack needed to achieve communication of numerous autonomous devices.

Brown (2010) [27] proposes a "Virtual Daily Behaviour Modeling and Anomaly Detection (ODHMAD)" model, whereby daily behaviour identification may be used to identify abnormalities along with behaviour modeling for unsociable adults in terms of their corporeal locations. In addition to this, ODHMAD includes the model for "online action recognition (OAR)" as well as the part "dynamic daily habit modeling (DDHM). In conjunction, OAR conducts web-based sensor data handling to identify routine workouts and critical occasions for the elderly. Nevertheless, this approach can not anticipate anomalous behaviour and subsequently includes additional sensors to discern the patient's behaviour. Suffice to say, this method of prediction is significant; as it is possible to predict and help an irregular state of the patient.

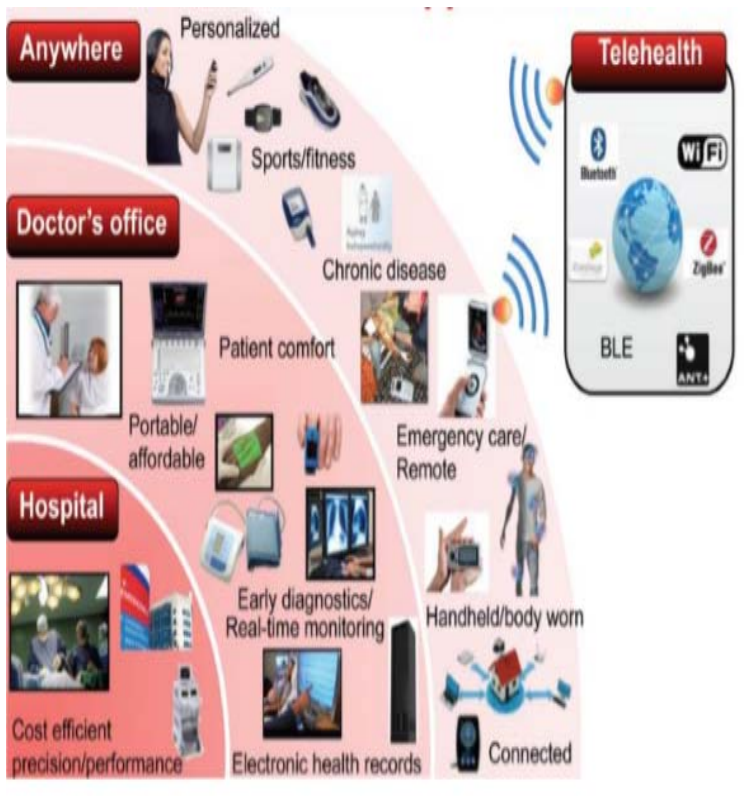

Fig. 5: Healthcare Trends and Opportunities Gandhi et al. (2017) [26].

Figure-5 illustrates the way the use of technology renders healthcare pervasive. It also indicates health-care developments and prospects.

Bui \& Zorzi (2011) [28], describes wellness to screen more weathered grown-ups' behaviour. They complete ongoing recognition of operation in elderly patients and evaluate the wellness function for the patients by applying the appliance-based practice. In addition, six kinds of sensors must be used to the monitoring environment. They recognize irregular behaviour in view of the data obtained from the environment as well as the use of the wellness feature, given the fact that they accomplish a low accuracy. Throughout their study, they used only two types of sensors in the predetermined cell, namely static sensors and ECG, and predicted both the ECG signal and the next position.

Darwish et al. (2019) [29] introduced MobiCare, a healthcare system concept that offers a wide range of health-related resources for mobile patients' effective healthcare services. In addition, this service consists of: (a) healthrelated service in clinical sensors and devices for remote deployment, re-configuration, selfactivation or even self-fixing with new health applications and services; (b) stable and safe dynamic software updating or upgrading service, used to local clinical system code as well as (c) remote body sensor enrolment and (re)configuration.

Das et al. (2019) [30], by progressively using a Markova logic network, discern the abnormal status for the patients. A model has been developed using IoMT that is particularly useful for patients with retinopathy and age-related macular degeneration (AMD). Different sensor kinds shall be deployed at different locations in the house on different objects. Their approach is aimed at identifying the patient's status by considering: (a) the tool used by the patient; (b) the time of arrival in a room; (c) the duration of stay in a room; (d) the patient's action, and (e) the possibility of simultaneous operation. Finally, they applied two learning methods: one to 
identify and detect the behaviour, and another to extract rule that shows the relation between those components and the status abnormality. The aim of this model is to provide the visually impaired patients who live alone particularly during the daytime with remote treatment. The model developed will also assess illness severity and potential risk associated with the same.

Datta et al. (2015) [31] used neural networks to predict a patient's abnormal state by demonstrating the ECG sensor data obtained from the mobile sensors attached to the patient's body to improve the accuracy of ECG data. In addition, they have a solution that does not require any extra sensors that are uncomfortable to wear for patients. Certainly, the methods suggested can also detect movement, without the use of external sensors. It can be used in application for behaviour recognition. This approach is used to predict an irregular status for a patient based on ECG sensors by using a system of activity recognition. In addition, the activityrecognition method involves various sensors to track the patient's relevant data and physical status, making this an exorbitant errand. Besides, wearing five or six sensors on the body isn't helpful for a patient. While past works rely on the method of activity recognition to construct the accuracy of the mobile node data and to discern an irregular patient health status, their execution is costly due to the requirement of certain deferential sensors, and they are not advantageous for the patient.

Desai et al. (2015) [32] suggested an IoT architecture with a semantic gateway in it. It is used to transform the raw data from the sensors into useful information required for further research. The semantic gateway is made up of protocols to ensure much-needed interoperability between different 'things'. Data is read in such a way that we can distinguish in each cell the transient example of the patient's ECG data, and the probability of the patient's survival. In addition, a grid-based tree structure network reduces communication overhead in mobile node data collection.

According to Deshpande et al. (2019) [33], as 'smart devices' are used in healthcare, massive quantities of data are gathered from different sources. Emerging technologies and tools are to be used to allow effective use of the data. The authors provided available a comparative analysis of the different emerging technologies and techniques to analyze the data collected (Dhanvijay \& Patil (2019) [34]).

It is possible to demonstrated that the location of the patient, the term spent inside a given area and ECG data are connected with one another. The developed model is assembled with the end goal that is to provide a connection between these components. As it were, the temporal and spatial data of the patient may directly affect their fundamental parameters in situations, for example, the care home, in which the patient has a booked every day schedule. An ordinary ECG signal is identified with the time and the movement of the patient. In this way, between 11 p.m. and 7 a.m., when the patient is sleeping in bed, the ECG signal is different from when the patient is strolling to the kitchen to make breakfast, somewhere in the range of 8 and 9 a.m. Clearly, a standard ECG signal during resting hours isn't typical for physical evening exercises. Consequently, the assurance of an abnormal status for the patient exclusively through the observing of ECG sensors isn't exact (Dohr, et al.2010) [35].

The processing of medical data is the center of every IoT-based healthcare application. The use of wearable devices is a must in order to simplify the diagnosis and treatment process and provide patients with pervasive care. A model is developed to resolve the security and privacy issues relating to the data. It uses the combination of various encryption techniques and digital signature to tackle medical data-related security and privacy concerns (Dwivedi et al. 2019) [36]. According to Raghupathi \& Raghupathi (2013) [37], "healthcare analytics solutions are a collection of decision support technologies built for healthcare professionals to gain insight and make healthcare decisions better and faster." The authors described various phases of health care analytics and built a conceptual framework that explains the relationship between different components of health care analytics. The Health Level Seven (HL7) specification was initially used by large organizations to ensure 
interoperability between different IoT devices. Lumba \& Bagula (2017) [38] suggested a model that would standardize the sharing of information between various healthcare agencies using a cloud-based platform. They have made a tradeoff between the data transmission model "inband" and "out-band." Their analysis revealed that "out-band" model in which data is translated into HL7 format at the destination is more effective than the "in-band" model in which data is translated into HL7 before transportation.

Real-time healthcare IoT systems need faster processing of generated data during crucial situations. Cloud platform centralized architecture fails to meet the necessary operating speed. Fog computing brings closer computational power and data resources. Much effective use of distributed resources is possible when both are integrated. In terms of speed and precision, this results in the best possible result (Mahmud et al. 2018) [39].

When using Big Data solutions to determine relevant correlations for data analysis reasons the key challenge is to incorporate various tools and resources. Manogaran et al. (2018) [40] suggested an architectural framework comprising two sub-modules, Meta fog reduction (MF-R) and grouping and choosing (GC). MF-R incorporates a range of analytical resources and technologies whereas GC provides the necessary protection for the data collected. It operates between fog and cloud platforms to give sensitive data the necessary protection. The authors also assessed the performance of their proposed model and found it to be effective in terms of resource utilization and security.

According to Greco et al. (2018) [41], sensors and wearable devices send the data needed for analysis regularly. Often in the emergency situation, the data may contain irregular or anomalous patterns. Various analytical systems use different techniques to identify unusual patterns in the data. Data irregularities are identified using cluster and edge computing technologies. The algorithm used to identify the substantially different patterns in the data is the hierarchical temporal memory (HTM).

Cruz et al. 2006 [42], examined the efficiency of different cancer-predicting AI techniques. The AI techniques can be used for cancer susceptibility or risk assessment, cancer recovery, and cancer recurrence. Rather than performing tissuedestructive experiments or relying on genomics, AI algorithms use image information to identify patients with more serious risks, who require more critical care. This would also help doctors know which patients suffer from a less severe cancer, and can prevent side effects of chemotherapy. It can be easily predicted using ML, ANN, SVM. With the support of ML, doctors can better understand the nature of tumor growth. They also showed the use of decision trees in cancer tissue prediction rather than opting for a biopsy, since certain organs contain both malignant and non-malignant tissues. The authors have clarified the procedure being painless, quick, and reliable at cost-effectiveness.

Analysis of medical images can be used to diagnose certain diseases, such as cancer, exactly. Predictive modeling involves an analysis of some variables' influence on future outcomes. When these two disciplines are integrated, the severity of a disease can be predicted with accuracy. Image processing techniques are used to classify images, and then the fussy $\mathrm{C}$-means clustering algorithm is used to correctly identify the similarities and differences between different pixels in a cluster and predict the illness. As the traditional approach is painful and timeconsuming, this approach is found to be successful (Palani \& Venkatalakshmi, 2018) [43].

IoT combines many heterogeneous organizations such as business, technology, healthcare, community, etc. The complexity of the problem increases as there is an increased number of stakeholders. When proper consideration is made of the flow of knowledge between different healthcare system institutions, the solution to a problem becomes simple. Pang et al. (2013) [44], created a model called in-home healthcare station (IHHS) for the efficient flow of information, which handles information flow effectively. They explained their model's efficacy with the help of multiple use cases. Paschou et al. (2013) [45] justified the use of IoT in healthcare for successful disease prediction. When 'things' are combined with software, the transfer of vast 
volumes of data imposes on the device costs of communication and overheads. They suggested a metric for determining network utilization and communication overhead in case of different protocols. They also emphasized the need to tackle security and privacy concerns related to health care data.

Health monitoring of patients is an activity in which WSNs take the lead role. Patients can be tracked periodically, with the support of these networks. Zigbee is an inexpensive, energyefficient, wireless networking technology. Ns2 simulator is used to test Zigbee Network activity in various scenarios. The output is assessed by considering the packet delivery rate (PRD), throughput, network latency, and energy usage parameters and analyzed using patient real-life data. The performance review guarantees Zigbee can be used successfully in applications for patient monitoring (Sharma et al. 2014) [46].

Robots are used for a wide variety of operations such as manufacturing, household, business, and so on. Internet if medical robotics (IoMRT) is a healthcare division that makes extensive use of robotics. The automation has led to robotic technology being developed.

Guntur et al. (2019) [47] proposed a conceptual model integrating IoMRT and Li-Fi technologies and analyzing the issues and challenges connected with the same. Li-Fi is used to overcome the speed and bandwidth issues associated with Wi-Fi.

Blockchain is a method by which data is securely stored in a decentralized network. It is an alternative to conventional cloud storage. The indisputable feature of blockchain is drawing the attention of the healthcare sector. Voluminous medical records can be stored effectively ensuring their security and privacy. Since healthcare data is used by many entities other than hospitals, this technology can be used to effectively handle interoperability (Yoon 2019) [48].

\subsection{A FEW USE CASES OF IOT} APPLICATION IN HEALTHCARE

In using IoT massive, lumbering paper registers can be replaced with a computerized, centralized database, which can also be improved in terms of unwavering continuity via block chains and expertise; a single administration system can collect information, preferably support control lines and monitor individuals through their mobile phones; all hardware can also be monitored and regulated (In rare situations, e.g., shut down). Such innovations will significantly help reduce in-house clinical costs, avoid monotonous work and make life simpler for patients and clinical staff alike. The overall productivity will also increase due to the ability of the robotized experienced structures to rapidly interpret medical problems that may take a long time to diagnose live specialists somewhere or other (Babu et al. 2016) [49].

\section{Remote patient monitoring system}

Remote Patient Monitoring uses mobile apps to gather patient data. The mobile apps manage both patient and device interactions. Comprehensive data relating to a patient will now be recorded in the EHR of each patient, which includes information on patient health in electronic format. The system accepts patient information and stores it in EHR. The data thus stored is used by Data Analytics Software to provide a comprehensive analysis of the present conditions of the patient's health. The analysis report will be sent to the doctor in the form of a notification and the doctor will inform the patient about the treatment with the help of a mobile app after going through the analyzed data. This may also be called mHealth (Jingjing et al. 2015) [50].

\section{Integrated health monitoring}

IoT permits the creation of a centralized network of interconnected devices capable of producing and exchanging data within a single system. All the data can be monitored and stored regularly, thereby providing persistent information storage. Patients suffering from chronic diseases (ChrDs) will have a number of health conditions which will become the cause for life-long suffering. Early detection of a ChrD will reduce the risk, because they need continuous care. Fighting ChrDs using IoT-controlled sensors, wearable devices, data analytics and portable devices is becoming increasingly inexpensive and flexible. The point is, monitoring and review of chronic medical conditions over large time periods is often necessary. In this way, slants in the variances of an ailment can be assessed and 
measured for proficiency. All is accomplished by using an IoT platform with a mix of block-chain and AI providing various additional capabilities in addition. (Kai et al. 2013) [51].

\section{Breast cancer detection}

Cancer prediction techniques may be used to assess cancer susceptibility or risk, cancer recuperation and cancer recurrence. Instead of carrying out tissue-destructive tests or relying on genomics, AI algorithms that take advantage of image information to identify patients with more severe illnesses who require more intensive treatment. It will also let physicians know which patients suffer from less serious cancer, and would be able to avoid chemotherapy side effects. This can be easily predicted using ML, ANN, SVM. With the help of ML, doctors can better understand the essence of cancer development. Also, the cancer perdition test can be used to estimate mortality due to disease. Timely and appropriate breast cancer diagnosis will save thousands of lives. The breast is composed of malignant and non-malignant cysts. Precise detection of these cysts is time consuming using traditional method. Abdrabou et al. (2010) [52] developed a framework called case-based reasoning (CBR), using historical data for quantitative analysis purposes.

\section{Diabetes prediction}

Risk factors for diabetes mellitus include family history, environmental factors, lifestyle, food habits, weight loss, and lack of physical activity, high blood pressure and cholesterol levels. Patients with diabetes mellitus must undergo a full clinical examination to check glucose levels, blood pus levels and function of the kidneys. Values can be gathered from clinical examination for attributes such as age, gender, blood pressure, RBC count, WBC count, random blood glucose levels, appetite, albumin level, Creatinine level, potassium level, pedal edema information, wounds etc. Other than this, the collection and preservation of historical patient data is also important. If the disease is not treated properly, kidney function can become maladaptive. When the kidneys stop working, the patient must undergo dialysis or transplantation which is painful and expensive. The progression can be predicted based on the aforementioned variables. Harisekaran (2015) [53] A correlation model is used to identify the necessary data, which categorizes data and uses techniques such as KNN, Decision Tree, SVM, Logical Regression or Random Forest to predict the future situation of the disease.

According to Sisodia \& Sisodia (2018) [54], diabetes is a chronic condition that develops when the insulin is no longer produced by the pancreas, or when the body cannot make substantial use of the insulin it generates. Individuals with diabetes are at higher risk of having certain serious health issues. Consistently high levels of blood glucose can lead to serious diseases that affect the heart and blood vessels, skin, kidneys, nerves and teeth. However, people with diabetes often face a greater risk of developing infections. Diabetes is a leading cause of cardiovascular disease, blindness, kidney failure and lower limb amputation, etc. Maintaining levels of blood glucose, blood pressure, and cholesterol at or near average can help to prevent or avoid complications of diabetes. Therefore, people with diabetes need regular monitoring. They developed a model for the detection of diabetes. It required the analysis of large amount of historical data. They used classification algorithms namely decision tree, SVM and Naïve Bayes that prognosticate the likelihood of diabetes in patients with maximum accuracy.

\section{Blood pressure (BP) monitoring and prediction}

According to $\mathrm{Wu}$ et al. 2014 [55], high blood pressure, or hypertension, occurs when blood pressure rises to unsafe levels. Many individuals do not feel symptoms or anything. The condition can take years or even decades to reach amounts severe enough for symptoms to become apparent. Such symptoms may be related to other problems however. Severe hypertension symptoms can include: headache, shortness of breath, nosebleeds, flushing, dizziness etc. High blood pressure is risky because it makes pumping the blood out to the body difficult for the heart and leads to stiffening the arteries or leads to atherosclerosis, stroke, kidney disease and heart failure. If BP is recorded on a regular basis by using wearable devices, advancement of the 
disease can be predicted. Using machine learning algorithms, the progress of the disease can be easily predicted when blood pressure and other associated variables such as body mass index, cholesterol level, etc. are analyzed. Blood pressure is a critical factor for preventing cardiovascular disease. Deep learning techniques can be used to evaluate the variation in blood pressure by analyzing time-series data such as pulse, cuff-fit, measurement time frame, etc., and contextual variables such as age, gender, medical history, present illness, habits etc. Koshimizu et al. (2020) [56] developed a model that uses deep algorithms to carry out the research.

\section{Parkinson patient monitoring}

Parkinson's disease is a progressive movementaffecting disease. It is a disease that causes a significant risk to the elderly and reduces their quality of life. There is no proper testing procedure for Parkinson's disease. Examination of the symptoms enables early identification. Patients with Parkinson need to be monitored at all times. IoT Healthcare systems have a solution. Research findings such as "Movement Disorder API" can detect irregular movements, step-length instability in patients. The doctor analyzes data stored in cloud and suggests proper action that must be taken. Shamli \& Sathiyabhama (2016) [57].

\section{7. 'Smart' ICU monitoring}

Within a conventional ICU (Intensive Care Unit) circumstance, the operator or the caregiver concerned will monitor the patients continuously without even committing a single mistake, but in the current situation smart IoT-based devices are used in the ICU, which can monitor the patient's condition and send the data continuously. In case of emergency, alert messages are sent to physician who will suggest further action (Sharma \& Kalra 2018) [58].

\section{Kidney disease monitoring and prediction} Chronic kidney disease (CKD) has multiple factors. It may be due to any other $\mathrm{ChrD}$, including obesity, diabetes, high BP, etc. CKD occurs when disease hinders kidney function, causing slowdown of working. Damage to the renal system impedes adequate blood filtration. As a consequence, the accumulation of fluid and waste in the body will cause many health complications. when the condition is acute dialysis or transplantation becomes essential. AI has the ability to customize patient care and to help clinicians identify points of intervention in patients at risk before dialysis or an organ transplant is needed. In order to predict CKD, online medical decision support system (OMDSS) is implemented where the vast amount of training data is stored in the cloud compared with patient test data collected from medical IoT devices using algorithms to predict disease severity and recommend effective care (Arulanthu \& Perumal 2020) [59].

\section{Asthma prediction}

Asthma is a ChrD present in people of all ages for which there is no effective treatment. If it becomes extreme it causes breathing problems. Several allergens cause asthma. The risk factors include family history and weakened immune systems, or things found in wheat such as chocolates, nuts, egg whites, milk, shellfish or gluten. The causes may be saliva, wool or pet hair, pharmaceutical products containing penicillins, salicylates or sulfonamides. There are several trigger tests to confirm. Popular among them are blood test, prick test and patch test. Such tests however are time-consuming and expensive. They may need to be replicated several times to identify the true allergen. Predicting risk for adverse incidents with asthma using reliable and timely surveillance data can guide prompt and tailored measures to reduce asthma's societal burden. Techniques such as ANN, decision trees, and analytics of big data will predict the illness and provide the healthcare support required (Ram et al. 2015) [60].

\section{Cardiovascular disorder prediction}

Cardiovascular disease (CVD) is a leading global cause of morbidity and mortality. CVDs include trouble with the heart valve, heart attack, stroke, arrhythmia, heart failure etc. CVD prevention requires early recognition of people with increased risk and implements successful changes in diet, lifestyle, or medication usage. Heart-rate can indicate a lot about a person's overall health. Early detection of CVD's will save many lives. Identifying the magnitude of a disease, identifying the risk factors associated with such disease are the main elements of CVD 
prediction systems. Wearable devices can monitor temperature, heart rate other quantitative information. Additionally, clinical IoT devices can detect blocks in the circulation system due to blocking up of cholesterol, irregular heartbeats, heart enlargement, etc. Such data are compared to the training data using predictive algorithms to reliably assess disease frequency and development (Chattergy et al. 2017) [61].

\section{Robotic Surgeries}

The advancement in connecting technology and increased complication in surgeries lead to the use of robotic devices in complicated operations. The tiny robotic devices can untiringly perform complicated operations inside the body of the patients (Patel et al. 2017) [62].

\section{2. 'Smart' nutrition monitoring}

Malnutrition is a disease in which the body is deficient of essential nutrients needed to maintain healthy tissue and the functioning of the heart. Sustaining the right balance in food intake is very significant, particularly for as it directly affects their growth. Over-nutrition contributes to obesity where the body's immunization mechanism weakens as a result of undernutrition. IoT-based smart nutrition monitoring helps the consumer to know the nutrients and calories to be consumed in the food and to recommend the correct meal pan to maintain a healthy diet. (Sundaravadivel et. al. 2018) [63].

\subsection{IOT BASED PERSONALIZED} HEALTHCARE DEVICES

Advances in sensor technology have modified traditional health-care systems, replacing it with wearable, person-centered health-care systems. Wearable monitoring systems can provide continuous health data, as well as better knowledge about people's general health. Sensors must be reliable and they must be energy efficient. They can be classified as on-body (wearable devices), off-body (attached to clothing and other accessories) and in-body (implanted rather than wearing, for example: pace-maker). The monitoring devices can be used to determine the rates of BP, ECG, blood glucose, respiration rate, heart rate, blood-oxygen, etc. (Yilmaz et al. 2010) [64]. The sensing devices that are extensively used in IoT based healthcare systems include
1. Wearable Fitness Trackers/Smart-watches: In the current scenario, it is very common to see people wearing fit bits that are incorporated with the IoT-based technology, which in turn provides the user with the actual heart beat rate and also the amount of physical activity done, amount of calories burnt etc. This whole process can be achieved when the fitness tracker is synchronized with the smart-phone app (Ullah et al.2017) [65]. 2. Sleep Monitoring Band:It is an on-body device is used to monitor sleep patterns, posture and other sleep related parameters. The device is helpful for the prediction and analysis of several diseases such as PD, insomnia, sleep apnea, dementia, etc. The device comes in two formsin the form of a wearable wrist band and another in the form of a headband (Chen et al. 2013) [66]. 3. 'Smart' contact lens: This device is so effective in nature that it can be used to make an early detection of the tear glucose level and also the early detection of the diabetes. In fact, this system can also measure the variation in the size of the patient's eye ball and this in turn helps in early detection and curing of Glaucoma. It can also be used in the treatment of diabetic retinopathy (Park et al. 2018) [67].

4. 'Smart' BP Monitoring unit: Heart Guide or Smart blood pressure monitor is a kind of wearable device based on IoT that is used to measure the patient's oscillometric blood pressure. Not only does it measure the daily level of blood pressure through certain daily activities such as distance travelled and the number of calories burnt. The recorded data is sent to the remote server which will then be made accessible for further review by the doctors (Tarouco et al. 2012) [68]

5. 'Intelligent' Inhaler : This IoT based device is quite effective in controlling the rates of asthma attacks among the patients. In this device there is a presence of sensors which are integrated with the inhaler and the inhaler in turn give alert messages to the concerned patient when they are about to counter any kind of asthma triggering objects such : air pollen and fluctuation of the surrounding temperature. In addition to this, by using this IoT based service the concerned patient will be able to combat with the respiratory related device for a longer period of time and also the 
records that are calculated by this IoT based device is very much accurate in nature which helps the doctor to take right decision regarding the patient (Islam et al. 2015) [69]

6. 'Smart' hearing aid: The hearing aid technology is now facing a new outlook focused on innovation of IoT-related hearing aid. Hardware and software innovations, which is of great use to people with progressive hearing loss difficulties. As the technologies advance quickly, the size of the hearing aid is getting smaller and the hearing aid's functionality is becoming more extensive, versatile and energyefficient. It can interact easily with other apps, as well. Hearing to a sound is very useful in a crowded environment (Li et al. 2017) [70].

7.Wearable cancer detector: Conventional cancer detecting methods are time-consuming, costly and painful. IoT based cancer detection is a process in which the concerned person has to wear the embedded device for 2 to 12 hours. The devices use ML algorithms to detect the cancer in early stage. They do not cause any undesirable side-effects on human body. Also, they will provide notification to the doctor and to the concerned patients by means of smart phones if any symptom is found (Ray et al. 2017) [71].

8. 'Intelligent' ECG System: ECG is a diagnostic tool that measures and records the electrical activity of the heart in detail. Interpretation of these details enables the diagnosis of a wide range of heart conditions from minor to life threatening. In case of patients suffering from CVDs, continuous monitoring is required. IoT-based ECG monitoring system can be used for long-time health monitoring in home environment. The device is widely adopted to diagnose and assess major health risks and chronic CVDs (Spano et al. 2016) [72].

9. 'Smart' bandages: The smart bandage has a special processor and sensors built into it that continuously track how the wound recovers. Smart bandage can detect signs of infection or swelling in time with the aid of specialized sensors that measure the wound's temperature and $\mathrm{pH}$. Thus, it will provide the antibiotics required directly to the skin. Also, there are IoT based smart solutions that manufacture a wide-range of personalized skincare products (Ianculescu et al.
2018) [73].

10. 'Smart' Pills: These are indigestible sensing devices which are commonly used in healthcare to provide stomach-related information such as the effect of medication or food on the gastrointestinal system. They can give photographs of organs within the stomach and analyze certain fluid and other contents inside the stomach (Kalantar-zadeh et al. 2017) [74].

4.6 ADVANTAGES \&CHALLENGES OF IOT BASED HEALTHCARE SYSTEM

\section{Advantages}

- Exceptional technological improvement: Unnecessary hospital visits, inactive aggregation of data, in-depth clinical report evaluation, etc., have become irrelevant that now ubiquitous healthcare makes use of technological innovations to provide outstanding healthcare (Karakra et al. 2019) [75].

- Accessibility: Doctor will also be able to see all essential patient data on request and will be able to monitor conditions constantly without physical presence in clinics

- Cost Saving: Probably the best favorable position of IoT in the field of healthcare is that productive self-sufficient frameworks will not so much costly for overseeing and 'utilizing' for a long period of time. Things are surprisingly better in the context of the patient cost investment funds due to the less clinic travels less laboratory tests (Lee et al., 2019) [76].

- Scalability: With the advancement in communication technology it is possible to inter-connect any number of devices because there will be billions of interconnected devices in near future. Alharthi, H. (2018) [77].

\section{Challenges}

- Data from multiple sources: Medical information is of heterogeneous type. Data should be obtained, processed and analyzed from diverse sources such as X-Ray images, ECGs, Ultra-Sound Scanning, medical records etc. Because they're from different sources, they'll certainly be in distinct 
format. The greatest challenge is to store the data from diverse sources. Different data formats would certainly make it a difficult job to pick appropriate parameters so that they can be properly stored (Ed-Daoudy \& Maalmi 2019) [78].

- Select acceptable information: Wearable devices send the data to the server continuously. Choosing the appropriate data is a challenge as useful data, noise and incoherent data may be present. The data can also be quantitative partially-structured, and unorganized. It is very important to only identify relevant data and to analyze everything.

- Shortage of memory: IoT devices and sensors can general huge amount of information, which are all significant and should be broken down. This suggests There will be difficulty in recovery of massive amount of data if lost due to lack of proper security measures.

- Underdeveloped initiatives: Numerous IoT initiatives coordinated at engaging chronic illnesses or different issues despite everything need time to develop and grow. Moreover, this technological specialty overall must grow a ton so as to begin giving standard improvement results (Kamel et al.2011) [79]

- Difficulties with regular update: By means of a huge amount of hardware solution come as a lot of software for controlling and supervising the whole thing. Along with that, this software has to be timely modernized for running effortlessly as well as remaining at its most recent version. Also, here is the place steady updates will need a lot of effort and would produce numerous specialized issues.

- Privacy and security issues: Voluminous data needs to be protected properly. Safeguarding the sensitive information is the most challenging task. The IoT-powered medication is the hardware-backed framework that capacities through the Internet. Moreover, online system gets breached and hacked. Ensuring privacy and security is a potential challenge.

- Worldwide healthcare guidelines: An IoT despite everything must be endorsed by worldwide healthcare administrative bodies around the world. Besides, it will require some serious energy and may keep numerous advancements under control in light of certain customs (Kang, et al., 2018). [70]

Table-1: Some useful fitness tracking mobile apps (Islam et al. 2015) [69]

\begin{tabular}{|l|l|l|l|}
\hline SN & Name & Company & Description \\
\hline 1 & Health Assistant & Mormoso \& Friends & $\begin{array}{l}\text { Monitors a broad variety of health parameters such } \\
\text { as body weight, temperature, lipid profile, glucose } \\
\text { level, BP, body water and fat and many other } \\
\text { physical activity based parameters }\end{array}$ \\
\hline 2 & Google Fit & Google & $\begin{array}{l}\text { Tracks user's walking, running and cycling } \\
\text { activities and shows distance, time, calories burnt }\end{array}$ \\
\hline 3 & Pedometer & $\begin{array}{l}\text { ITO Technologies, } \\
\text { Inc. }\end{array}$ & $\begin{array}{l}\text { Records number of steps taken by the user and } \\
\text { gives output such as walking speed, calories burnt, } \\
\text { distance, etc. allows users to set fitness goals }\end{array}$ \\
\hline 4 & $\begin{array}{l}\text { Water Drink } \\
\text { Remainder }\end{array}$ & Leap Fitness Group & $\begin{array}{l}\text { Reminds user to drink water and tracks water- } \\
\text { drinking habits of the user }\end{array}$ \\
\hline 5 & Period Calendar & Simple Design Ltd. & $\begin{array}{l}\text { Keeps track of the period, and ovulation days and } \\
\text { helps the user achieve or prevent pregnancy }\end{array}$ \\
\hline 6 & $\begin{array}{l}\text { Body } \\
\text { Temperature }\end{array}$ & Brandish Apps & $\begin{array}{l}\text { Keeps track of body temperature and identifies its } \\
\text { severity }\end{array}$ \\
\hline 7 & Eye Care Plus & healthcare4mobile & Tests and monitors vision \\
\hline 8 & $\begin{array}{l}\text { Instant Heart } \\
\text { Rate }\end{array}$ & azumio & $\begin{array}{l}\text { Measures heart rate using smartphone's built in } \\
\text { camera }\end{array}$ \\
\hline
\end{tabular}




\begin{tabular}{|l|l|l|l|}
\hline 9 & uHear & unitron & Allows for self assessment of hearing \\
\hline 10 & SkinVision & SkinVision B.V. & $\begin{array}{l}\text { Keeps track of user's skin health and enables the } \\
\text { early discovery of skin disease }\end{array}$ \\
\hline 11 & Arogya Setu & $\begin{array}{l}\text { National Informatics } \\
\text { Centre }\end{array}$ & $\begin{array}{l}\text { To bring awareness of health among Indians } \\
\text { particularly regarding Covid-19 and link essential } \\
\text { health facilities (Khanna et. al 2020) [80] }\end{array}$ \\
\hline
\end{tabular}

This is a list of selected technologies that have a significant effect on making it accessible and universal for children and elderly care. As time goes by, technology is becoming more advanced and more innovative devices and applications can be provided with numerous features and improved fuel efficiency.

\subsection{SUMMARY OF RELATED WORK}

- Table-2: Review of findings presented by different authors between 2010 and 2020 .

\begin{tabular}{|c|c|c|c|}
\hline $\mathbf{S N}$ & Author(s) & Year & Inventions/Findings/Results \\
\hline 1 & Brown [27] & 2010 & $\begin{array}{l}\text { Envisaged ODHMAD model for discovering } \\
\text { abnormalities in elderly people's behaviour. }\end{array}$ \\
\hline 2 & Dohr [35] & 2010 & $\begin{array}{l}\text { Mentioned that there is a correlation between temporal and } \\
\text { spatial data about patients collected using intelligent } \\
\text { devices }\end{array}$ \\
\hline 3 & Abdrabou et al. [52] & 2010 & $\begin{array}{l}\text { Developed a model called CBR to accurately classify } \\
\text { different stages of breast cancer. }\end{array}$ \\
\hline 4 & Yilmaz et al. [64] & 2010 & $\begin{array}{l}\text { Explained how portable IoT devices are used to provide } \\
\text { continuous healthcare. These sensing devices were also } \\
\text { classified according to their use. }\end{array}$ \\
\hline 5 & Bui \& Zorzi [28] & 2011 & $\begin{array}{l}\text { Exemplify the use of IoT technology to make quick and } \\
\text { efficient assessments during emergency situations. }\end{array}$ \\
\hline 6 & Taroucoet al. [68] & 2012 & $\begin{array}{l}\text { Discussed the use of off-shelf IoT tools used to track } \\
\text { patients continuously at home. A ISO demonstrated the } \\
\text { need for proxy-agent access to the IoT infrastructure. }\end{array}$ \\
\hline 7 & $\begin{array}{l}\text { Raghupathi \& Raghupathi } \\
\text { [37] }\end{array}$ & 2013 & $\begin{array}{l}\text { Developed a conceptual model consisting of } 4 \text { levels } \\
\text { which highlights the components of the framework for } \\
\text { health care analytics. }\end{array}$ \\
\hline 8 & Kai et al. [51] & 2013 & $\begin{array}{l}\text { Developed a model that integrates several emerging } \\
\text { technologies for providing secure healthcare solutions }\end{array}$ \\
\hline 9 & Babu et al.[13] & 2013 & $\begin{array}{l}\text { Proposed a conceptual architecture for remote monitoring } \\
\text { of patients, where cloud technology is used to store patient } \\
\text { data. }\end{array}$ \\
\hline 10 & Chen et al.[66] & 2013 & $\begin{array}{l}\text { The use of wireless sleep / wake-up monitoring system } \\
\text { used in deep brain study of PD patients was demonstrated }\end{array}$ \\
\hline 11 & Pang et al. [44] & 2013 & $\begin{array}{l}\text { Developed a creative business strategy for the application } \\
\text { of IoT in healthcare, bridging the gap between technology } \\
\text { and various business strategies. }\end{array}$ \\
\hline 12 & Jiong et al. [15] & 2014 & $\begin{array}{l}\text { Developed layered service broker network architecture for } \\
\text { personalized cloud healthcare system to address the } \\
\text { drawbacks of traditional healthcare framework }\end{array}$ \\
\hline 13 & Wu et al. [55] & 2014 & $\begin{array}{l}\text { Illustrated the use of machine learnig techniques for the } \\
\text { effective prediction of blood pressure and related diseases } \\
\text { caused by it. }\end{array}$ \\
\hline 14 & Sharma et al. [46] & 2014 & $\begin{array}{l}\text { Conducted the performance evaluation of the Zigbee } \\
\text { sensor network for remote patient monitoring systems, }\end{array}$ \\
\hline
\end{tabular}




\begin{tabular}{|c|c|c|c|}
\hline & & & $\begin{array}{l}\text { taking into account PDR, throughput, energy consumption } \\
\text { and network latency }\end{array}$ \\
\hline 15 & Caban et al. [9] & 2015 & $\begin{array}{l}\text { Explained how IoT apps and EHRs are being used in } \\
\text { modern healthcare. Highlighted the drawbacks and } \\
\text { benefits of the data visualization tools. }\end{array}$ \\
\hline 16 & Datta et al. [31] & 2015 & $\begin{array}{l}\text { Developed IoT infrastructure in 'smart homes' to provide } \\
\text { personalized healthcare services. }\end{array}$ \\
\hline 17 & Desai et al. [32] & 2015 & $\begin{array}{l}\text { Suggested an IoT architecture using semantic gateway to } \\
\text { streamline communication between 'things' and provide } \\
\text { intelligent solutions to healthcare. }\end{array}$ \\
\hline 18 & Harisekaran [53] & 2015 & $\begin{array}{l}\text { Designed a predictive model that uses correlation matrix } \\
\text { for diabetes prediction. The model uses different } \\
\text { techniques of classification to assess various variables in } \\
\text { the data set such as blood glucose level, BMI, blood } \\
\text { pressure etc. }\end{array}$ \\
\hline 19 & Islam et al. [69] & 2015 & $\begin{array}{l}\text { Conducted a survey of different aspects related to IoT } \\
\text { enabled healthcare systems, and identified different } \\
\text { technologies used in healthcare based on IoT. }\end{array}$ \\
\hline 20 & Ram et al. [60] & 2015 & $\begin{array}{l}\text { Explained how environmental data can be leveraged to } \\
\text { predict asthma. The analyzing techniques used are ANN } \\
\text { and decision trees. }\end{array}$ \\
\hline 21 & Parikh et al.[12] & 2016 & $\begin{array}{l}\text { Narrated the application of 'precision medicine' and } \\
\text { 'precision delivery' using EHR data to provide } \\
\text { personalized health care services. }\end{array}$ \\
\hline 22 & Yeh [17] & 2016 & Proposed a model for IoT based HC solution using BSN. \\
\hline 23 & Kodali et al. [24] & 2016 & $\begin{array}{l}\text { Described the need for IoT and Cloud infrastructure to } \\
\text { manage patient data in a structured way. }\end{array}$ \\
\hline 24 & Babu et al. [49] & 2016 & $\begin{array}{l}\text { Demonstrated the use of RFID tags for remote monitoring } \\
\text { of patients }\end{array}$ \\
\hline 25 & $\begin{array}{l}\text { Shamli \& Sathiyabhama } \\
\text { [57] }\end{array}$ & 2016 & $\begin{array}{l}\text { Demonstrated the use of machine learning techniques to } \\
\text { identify disorders in patients suffering from Parkinson's } \\
\text { disease }\end{array}$ \\
\hline 26 & Spano et al.[72] & 2016 & $\begin{array}{l}\text { Envisaged wireless ECG monitoring system that } \\
\text { integrates multiple heterogeneous applications using IoT } \\
\text { platform. }\end{array}$ \\
\hline 27 & Chui et al.[16] & 2017 & $\begin{array}{l}\text { Analyzed new optimization algorithms and machine } \\
\text { learning algorithms to select the best algorithm for } \\
\text { designing an IoT solution. }\end{array}$ \\
\hline 28 & Lin et al. [21] & 2017 & $\begin{array}{l}\text { Proposed a predictive model called BMLT to analyze } \\
\text { several risks associated with a single disease such as } \\
\text { diabetes or obesity }\end{array}$ \\
\hline 29 & Wu et al. [22] & 2017 & $\begin{array}{l}\text { Proposed a model called WBAN implementing energy } \\
\text { harvesting mechanism comprising of wearable solar } \\
\text { powered devices. }\end{array}$ \\
\hline 30 & Joyia et al. [25] & 2017 & $\begin{array}{l}\text { Suggested the implementation of IoT to transform 'things' } \\
\text { into 'smart things' and provide innovative solutions in } \\
\text { healthcare. }\end{array}$ \\
\hline 31 & Chattergy et al. [61] & 2017 & Described IoT-based healthcare systems stakeholders and \\
\hline
\end{tabular}




\begin{tabular}{|c|c|c|c|}
\hline & & & $\begin{array}{l}\text { clarified how different algorithms are used to accurately } \\
\text { predict CVD. }\end{array}$ \\
\hline 32 & Ullah et al. [65] & 2017 & $\begin{array}{l}\text { Proposed a lightweight model to guarantee } \\
\text { interoperability among heterogeneous IoT devices. } \\
\text { An analysis of the various IoT devices and protocols was } \\
\text { also undertaken. }\end{array}$ \\
\hline 33 & Ray et al. [71] & 2017 & $\begin{array}{l}\text { Discussed the use of many wearable devices which could } \\
\text { be used to identify various cancers. Demonstrated cancer } \\
\text { detecting device based on ultra-wide band transmitter. } \\
\text { Mentioned issues and challenges with Wearable } \\
\text { Technology. }\end{array}$ \\
\hline 34 & Patel et al. [62] & 2017 & $\begin{array}{l}\text { Presented the robotic system architecture, the issues, } \\
\text { problems and advantages of using robots in complex } \\
\text { surgeries. }\end{array}$ \\
\hline 35 & Lumba \& Bagula [38] & 2017 & $\begin{array}{l}\text { Proposed a system to ensure interoperability between } \\
\text { different IoT devices, and investigated HL7's } \\
\text { effectiveness in cloud-based environment. }\end{array}$ \\
\hline 36 & Gandhi \& Ghosal [26] & 2018 & $\begin{array}{l}\text { Provided conceptual framework and protocol stack } \\
\text { necessary for the information exchange between multiple } \\
\text { IoT devices. }\end{array}$ \\
\hline 37 & Knickerbocker et al. [23] & 2018 & $\begin{array}{l}\text { Recommended a model leveraging heterogeneous } \\
\text { technology to offer advanced health-care solutions }\end{array}$ \\
\hline 38 & Sisodia \& Sisodia [54] & 2018 & $\begin{array}{l}\text { Developed a diabetic detection model which uses different } \\
\text { classification techniques of machine learning }\end{array}$ \\
\hline 39 & Park et al. [67] & 2018 & $\begin{array}{l}\text { Highlighted the use of various types of smart contact } \\
\text { lenses used to diagnose sight-related issues caused by } \\
\text { diseases such as diabetes. }\end{array}$ \\
\hline 40 & Sundaravadivel et al. [63] & 2018 & $\begin{array}{l}\text { To ensure a healthy diet particularly for children, a } \\
\text { conceptual framework was developed to track the nutrition } \\
\text { level of the food. }\end{array}$ \\
\hline 41 & Azar et al.[14] & 2019 & $\begin{array}{l}\text { Developed data reduction algorithms using edge } \\
\text { computing to demonstrate energy conservation of IoT } \\
\text { devices during transmission using edge computing }\end{array}$ \\
\hline 42 & Sharma \& Kalra [58] & 2018 & $\begin{array}{l}\text { A powerful, lightweight, and secure verification scheme is } \\
\text { built to ensure authentication of patient data stored in the } \\
\text { cloud }\end{array}$ \\
\hline 43 & Mahmud et al. [39] & 2018 & $\begin{array}{l}\text { Developed an optimized framework using cloud and fog } \\
\text { technologies to enhance interoperability between different } \\
\text { IoT devices in the healthcare. }\end{array}$ \\
\hline 44 & Manogaran et al.[40] & 2018 & $\begin{array}{l}\text { Proposed two frameworks, namely MF-R and CG, to } \\
\text { pervasively track data from patients. GC architecture uses } \\
\text { key management to protect against unauthorized access to } \\
\text { data. }\end{array}$ \\
\hline 45 & Greco et al.[41] & 2018 & $\begin{array}{l}\text { Implemented healthcare IoT architecture to trigger alarms } \\
\text { during times of emergency. To ensure scalability it enables } \\
\text { use of edge and cluster computing. }\end{array}$ \\
\hline 46 & $\begin{array}{l}\text { Palani \&Venkatalakshmi } \\
\text { [43] }\end{array}$ & 2018 & $\begin{array}{l}\text { Proposed a model using fuzzy clustering algorithm to } \\
\text { conduct image analysis for accurate disease prediction. } \\
\text { The model produced more accurate results when }\end{array}$ \\
\hline
\end{tabular}

Geetha Poornima K, et al. (2020); www.srinivaspublication.com 


\begin{tabular}{|c|c|c|c|}
\hline & & & demonstrated using the real-life data. \\
\hline 47 & Ianculescu et al. [73] & 2018 & $\begin{array}{l}\text { Explained the use of several 'smart' products used for the } \\
\text { detection and treatment of skin related diseases. }\end{array}$ \\
\hline 48 & Ud Din et al. [6] & 2019 & $\begin{array}{l}\text { Designed 5-layered architecture for IoT systems } \\
\text { comprising of several components of IoT. }\end{array}$ \\
\hline 49 & Baig et al.[18] & 2019 & $\begin{array}{l}\text { Review undertaken that presents development in wearable } \\
\text { technology, the limitations and challenges associated with } \\
\text { wearable devices. }\end{array}$ \\
\hline 50 & Bhawiyuga et al. [19] & 2019 & $\begin{array}{l}\text { Recommended an IoT system architecture that } \\
\text { incorporates a middleware that functions as a } \\
\text { bridge between wearable devices and cloud platform. }\end{array}$ \\
\hline 51 & Boulos et al. [20] & 2019 & $\begin{array}{l}\text { Developed a model called GeoAI that combines AI and } \\
\text { geographic information of patients to provide better } \\
\text { solutions in several healthcare segments. }\end{array}$ \\
\hline 52 & Darwish et al. [29] & 2019 & $\begin{array}{l}\text { Developed an IoT cloud assimilation platform to } \\
\text { healthcare, and analyzed the associated issues and } \\
\text { challenges. }\end{array}$ \\
\hline 53 & Das et al. [30] & 2019 & $\begin{array}{l}\text { Developed a framework that is useful specifically for } \\
\text { visually challenged patients using IoMT. }\end{array}$ \\
\hline 54 & Deshpande et al. [33] & 2019 & $\begin{array}{l}\text { Carried out a detailed analysis of various tools and } \\
\text { techniques used to analyze the data generated via 'smart } \\
\text { devices' for decision making purposes. }\end{array}$ \\
\hline 55 & Dhanvijay \& Patil [34] & 2019 & $\begin{array}{l}\text { Proposed real-time monitoring system and architectural } \\
\text { framework for H-IoT. }\end{array}$ \\
\hline 56 & Dwivedi et al. [36] & 2019 & $\begin{array}{l}\text { Proposed IoT topology and a conceptual model to tackle } \\
\text { risks to the confidentiality and privacy of clinical data } \\
\text { using hybrid technology }\end{array}$ \\
\hline 57 & Guntur et al. [47] & 2019 & $\begin{array}{l}\text { Proposed a conceptual paradigm, called IoMRT, which } \\
\text { uses healthcare robotics. Analyzed the issues and } \\
\text { challenges pertaining to the same. }\end{array}$ \\
\hline 58 & Yoon $[48]$ & 2019 & $\begin{array}{l}\text { Explained the significance of using blockchain technology } \\
\text { in healthcare sector. }\end{array}$ \\
\hline 59 & Koshimizu et al. [56] & 2020 & $\begin{array}{l}\text { Developed a model that uses deep neural network to } \\
\text { variation of blood pressure and predict the progress of the } \\
\text { disease }\end{array}$ \\
\hline 60 & Arulanthu \& Perumal [59] & 2020 & $\begin{array}{l}\text { Built OMDSS for the prediction of CKD by using } \\
\text { classifier techniques to provide efficient healthcare and } \\
\text { evaluated the performance of different classifier } \\
\text { techniques using UCI dataset }\end{array}$ \\
\hline
\end{tabular}

\section{DISCUSSION :}

Technology is playing an integral role in the world today and all sectors are benefitting from what it has to offer. The health care sector is no exception. It can benefit significantly from predictive analytics, and it can be argued that this technology is a core aspect of the future of medicine and health care delivery in general.
(Karakra et al. 2019) [75]. The advantages associated with sensibly designed and implemented predictive analytics in the health care sector far outweigh their potential issues. Millions of people around the world stand to benefit from its adoption, with patients able to enjoy an improved service delivery that anticipates challenges and addresses them proactively. Diagnosis would be more accurate, 
as would the treatment that follows. Caregivers would also benefit, given how easy it would be to access useful information and take appropriate steps toward seeing the health of their patients improve (Lee et al. 2019) [76]. However, even with these advantages, there are many emerging risks that need to be navigated for all involved parties to benefit from the full potential of predictive analytics.

Mostly, this would involve setting clear risk controls to cover bias, address emerging ethical considerations, and ensure clearer documentation for accountability. With policymakers still moving to catch up with the drafting of appropriate legislation, this would require selfregulation from those responsible for writing the algorithms. Existing predictive models and analysis also need to avoid breaking any existing laws such as those around privacy or violating ethical standards (Kang et al. 2018) [81].

The healthcare system using IoT interconnects patients, clinical staff, care takers of patients, laboratories, pharmacies and so on. The healthcare system much depends upon the wearable devices for providing quantitative data about the patients. Undoubtedly, the wearable technology has made the process of diagnosis affordable, fast and less painful. But the data sent by these wearable devices is not accurate as expected. If the data is not accurate, certainly it is going to affect the prediction. Hence the designing of 'smart' devices is very much essential. According to "no free lunch theorem" of ML, "there is no unique algorithm that works best for every application". Hence, designing of appropriate algorithm for intelligent healthcare solution is a challenging job. The analysts have to select the optimal solution as the outcome of predictive system is life-critical one. The success depends much upon the complexity of problem, availability of training data and computational ability. There will be highly qualified clinical staff, state-of-the-art clinical equipment and intelligent IoT solutions but selecting an appropriate therapy is a challenging one (Thompson et al. 2008) [82].

When the patient is in critical condition, with his/ her health is continuously degrading, the clinical staff will have minimal technical expertise to deal with the complication. Training them to make the maximal use of technology is most essential. With the help of IoT solutions, physicians will be able to spend more time with their patients instead of scrolling the clinical records but it is very hard to convince the customer that the solution he receives is the best possible one. There must be some solid evidence to make the patient realize that the intelligent healthcare system will generate an optimal solution (Guazelli2011) [83].

\section{RESEARCH GAP :}

Predictive healthcare analysis using IoT involves the interconnection of two heterogeneous fields, namely the medical science and computer technology. The predictive solutions much rely on the data scientist's analytical capabilities. While they are experts in ML, AI or any other new technology, they would have very limited knowledge of medical science. That generates a friction between the two when it comes to sharing details. Each $\mathrm{ChrD}$ requires various techniques, different tools, and different algorithms. If prediction can be generalized, the solutions can be integrated for many more diseases. Using IoT, innovative health management system can be designed to maintain a healthy lifestyle by using healthcare APIs to provide personalized health management functionalities. This program monitors calorie intake, sleep information, and recommends diet, exercise, and yoga postures based on needs to ensure the user's overall health. From our review it is clear that the analysis of various health parameters involves many wearable devices. If there is an 'integrated IoT healthcare kit' which is an off-body device for checking several parameters such as body temperature, blood glucose level, heart rate, cholesterol level, BP, breathing rate, etc., it will reduce the discomfort caused by wearable devices, especially for patients suffering from high BP, diabetes, obesity, CVDs, etc.

Some of the research gap issues we found are:

Research Gap 1: Best health \& fitness technologies for the personalized healthcare.

Though IoT technology just emerging and is in its infant stage, a wide range of supporting devices such as sensors, actuators, processing elements, 
and storage based components are made available to the users and it would be difficult to represent a specific technology for any specific health requirements. In this regard, there is a huge scope for research to understand and find out an effective and reliable subset of technologies contributing to the development of individual and autonomous components of the intelligent health and fitness system.

Research Gap 2: Algorithms and Models behind PDA are not accountable or transparent.

Predictive analytics has a strong and healthy place in the future of health care delivery. However, we need to remember that the algorithms and models behind predictive analytics are not perfect and need to be made more accountable and transparent with clear human intervention points when appropriate. They also need a clear foundation to be set that seeks to be ethical and nonbiased in its application, preferably one guided by legislation.

Research Gap 3: Data sent by personal wearable devices are not accurate and precise.

The healthcare system using IoT interconnects patients, clinical staff, care takers of patients, laboratories, pharmacies and so on. The healthcare system much depends upon the wearable devices for providing quantitative data about the patients. Undoubtedly, the wearable technology has made the process of diagnosis affordable, fast and less painful. But the data sent by these wearable devices is not accurate as expected. If the data is not accurate, certainly it is going to affect the prediction. Hence the designing of 'smart' devices is very much essential.

Research Gap 4: Data related to individual patient is not stored in a single central database. The efficiency of an IoT solution depends more upon the feedback of the customer/patient. It may require several days or years to get the feedback as the IoT solutions discussed in this paper are for patients suffering from long-term illness. If entire data related to patients is stored in a single location such as 'all-at-one-place' it can be shared with care providers, care takers, pharmacy people and specialists (for second opinion) provided security and privacy issues are resolved.
Research Gap 5: Patient's privacy data must be adequately managed in compliance with privacy laws.

Predictive analytics using IoT enable data exchange to deliver more reliable outcomes. The wider the data sets, the better the probability of forecasts being correct. This sometimes contradicts the privacy principle and may jeopardize data if it is not adequately managed in compliance with laws and privacy controls. Greater dependency on technology ensures that individual need to ensure that ethical standards are continually met.

Research Gap 6: Efficient and effective IoT infrastructure is the need of the hour.

Patients, Doctors and Healthcare Management are interlinked in an IoT networks for the purpose of better healthcare service. The primary prerequisite for an IoT focused PDA is the use of apt connecting technology. Stakeholders will have access to these developments inside and outside the network. Which presents a range of financial, security, and privacy concerns? There is also a problem with low power consumption for IoT nodes backed by batteries, high-power requirements for physical devices, and, most notably, bandwidth utilization. Therefore, in resolving these issues there is research potential and seeking a solution for a secure and effective IoT infrastructure as regards its application to the education industry.

Research Gap 7: User must be provided with an optimal solution.

With the help of IoT solutions, physicians will be able to spend more time with their patients instead of scrolling the clinical records but it is very hard to convince the customer that the solution he receives is the best possible one. There must be some solid evidence to make the patient realize that the intelligent healthcare system will generate an optimal solution.

\section{RESEARCH AGENDA :}

(1) What data visualization and analytics algorithms are better for decision making?

(2) What technology can improve the privacy of sharing data across a large network of users and provide an immutable record of data transactions? 
(3) What framework will have the capability of improving users understanding of health conditions, providing patients with more information on their health risks, making health care more personalized and therapies more accurate

(4) What smart sensors and materials of increasing sophistication can allow products and materials to alter their behaviour based on external conditions such as $\mathrm{pH}$, temperature, electric fields and bacteria?

(5) What new technology platform can be proposed with the best use of IoT pedagogy and communication elements to incorporate an intelligent PDA system?

(6) What IoT Technology can be proposed for PDA that reduces the complexities of software, hardware, and connectivity and storage?

(7) What IoT framework can be proposed to connect the key stakeholders in the Healthcare system under one PDA solution?

(8) What integrated IoT system can be proposed to incorporate all the elements of PDA?

\section{CONCLUSION :}

Predictive health is well-defined as predictive analytics for health and healthcare improvement. That covers ground breaking data collection, state-of-the-art methodologies, various strategic partnerships, significant innovation, imaginative business and rigorous management and policies. In recent years, sources of health data have proliferated dramatically. Wearable data, embedded IoT data, patient social networking and several other forms of data are now a significant aspect of clinical data which influenced health-related decisions of individual and community. We advocate open access to data and analysis, the use of innovative preventive analytics to enhance health system performance and create an atmosphere that will enable for continuing health IT progress, for predictive healthcare to boost progress and become an economic force. It is an enormous opportunity for us to develop an integrated data framework to increase access to information and enterprise in a privacy-sensitive manner. That would render predictive wellbeing a significant engine of socio-economic progress in the health sector as a whole. We expect that researchers can very quickly come up with creative, well developed, standardized and user-friendly health data frameworks that help serve the safety of people and provide easy access for organizations and more efficient resources to interpret results. In our future work we will focus on the implementation of a fully developed, scalable technology focused IoT health system to improve an individual person's health economy and community in general.

\section{REFERENCES :}

[1] McConnochie, K. M., Conners, G. P., Brayer, A. F., Goepp, J., Herendeen, N. E., Wood, N. E., Roghmann, K. J. (2006). Effectiveness of telemedicine in replacing inperson evaluation for acute childhood illness in office settings. Telemedicine Journal and EHealth, 12(3), 308-316. DOI: https://doi.org/10.1089/tmj.2006.12.308.

[2] Kart, F., Miao, G., Moser, L. E., \& MelliarSmith, P. M. (2007). A Distributed e-Healthcare System Based on the Service Oriented Architecture. IEEE International Conference on Services Computing (SCC 2007). DOI: https://doi.org/10.1109/scc.2007.2.

[3] Almulhim, M., Islam, N., \& Zaman, N. (2019). A Lightweight and Secure Authentication Scheme for IoT Based E-Health Applications. IJCSNS International Journal of Computer Science and Network Security, 19(1), 107-120.

[4] Al-Turjman, F., \& Baali, I. (2019). Machine learning for wearable IoT-based applications: A survey. Transactions on Emerging Telecommunications Technologies. e3635. 1-16. DOI: https://doi.org/ 10.1002/ett.3635.

[5] Asghari, P., Rahmani, A. M., \& Haj Seyyed Javadi, H. (2019). A medical monitoring scheme and health-medical service composition model in cloud-based IoT platform. Transactions on Emerging Telecommunications Technologies, 30(6). DOI: https://doi.org/10.1002/ett.3637.

[6] Ud Din, I., Almogren, A., Guizani, M., \& Zuair, M. (2019). A Decade of Internet of Things: Analysis in the Light of Healthcare Applications. 
IEEE Access, 7, 89967-89979. DOI: https:// doi.org/10.1109/ACCESS.2019.2927082.

[7] Canada's Big Data Consortium. (2018). A Vision for Predictive Health. (May), 1-96. Retrieved from https://www.ryerson.ca/content/dam/provost/Ac cessiblePDFs/A_Vision for Predictive Health Print final.pdf

[8] Von Son, F. W., Ceballos, G. R., Rivera, H. M., Larios, V. M., Beltran, N. E., Beltran, R., ... Ascencio, J. A. (2017). Smart genetics for smarter health-an innovation proposal to improve wellness and health care in the cities of the future. 2017 International Smart Cities Conference, ISC2 2017.2 DOI: https://doi.org/10.1109/ISC2.2017.8090837.

[9] Caban, J. J., \& Gotz, D. (2015). Visual analytics in healthcare - opportunities and research challenges. Journal of the American Medical Informatics Association, 22(2), 260 262. DOI: https://doi.org/10.1093/jamia/ocv006.

[10] Yach, D., Hawkes, C., Linn Gould, C., \& Haman, K. J. (2015). I= SPECIAL COMMUNICATION. The Global Burden of Chronic Diseases Overcoming Impediments to Prevention and Control. 291(21). Retrieved from www.iama.com.

[11] Cohen, I. G., Amarasingham, R., Shah, A., Xie, B., \& Lo, B. (2014). The legal and ethical concerns that arise from using complex predictive analytics in health care. Health Affairs, 33(7), 1139-1147.

DOI:

https://doi.org/10.1377/hlthaff.2014.0048.

[12] Parikh, R. B., Kakad, M., \& Bates, D. W. (2016). Integrating predictive analytics into highvaluecare the dawn of precision delivery. JAMA Journal of the American Medical Association, 315(7), 651-652. DOI: https://doi.org/10.1001/jama.2015.19417.

[13] Babu, S., Chandini, M., Lavanya, P., Ganapathy, K., \& Vaidehi, V. (2013). Cloudenabled remote health monitoring system. 2013 International Conference on Recent Trends in Information Technology (ICRTIT). DOI: https://doi.org/110.1109/icrtit.2013.6844286.
[14] Azar, J., Makhoul, A., Barhamgi, M., \& Couturier, R. (2019). An energy efficient IoT data compression approach for edge machine learning. Future Generation Computer Systems, 96, 168175.

DOI: https://doi.org/10.1016/j.future.2019.02.005.

[15] Jeong, S., Kim, Y. W., \&Youn, C. H. (2014). Personalized healthcare system for chronic disease care in cloud environment. ETRI Journal, 36(5), 730-740. DOI: https://doi.org/10.4218/ etrij.14.2214.0070.

[16] Chui, K. T., Alhalabi, W., Pang, S. S. H., de Pablos, P. O., Liu, R. W., \& Zhao, M. (2017). Disease diagnosis in smart healthcare: Innovation, technologies and applications. Sustainability (Switzerland), 9(12), 1-23. DOI: https://doi.org/10.3390/su9122309.

[17] Yeh, K. H. (2016). A Secure IoT-Based Healthcare System with Body Sensor Networks. IEEE Access, 4, 10288-10299. DOI: https://doi.org/10.1109/ACCESS.2016.2638038.

[18] Baig, M. M., Afifi, S., Gholam Hosseini, H., \& Mirza, F. (2019). A Systematic Review of Wearable Sensors and IoT-Based Monitoring Applications for Older Adults - a Focus on Ageing Population and Independent Living. Journal of Medical Systems, 43(8). DOI: https://doi.org/10.1007/s10916-019-1365-7 .

[19] Bhawiyuga, A., Pramukantoro, E. S., \& Kirana, A. P. (2019). A Web of Thing Middleware for Enabling Standard Web Access Over BLE based Healthcare Wearable Device. 2019 IEEE 1st Global Conference on Life Sciences and Technologies (LifeTech). DOI: https://doi.org/10.1109/ lifetech.2019.8883981.

[20] Kamel Boulos, M. N., Peng, G., \& VoPham, T. (2019). An overview of GeoAI applications in health and healthcare. International Journal of Health Geographics, 18(1). DOI: https://doi.org/ 10.1186/s12942-019-0171-2.

[21] Lin, Y., Chen, H., \& Brown, R. A. (2017). Healthcare Predictive Analytics for Risk Profiling in Chronic Care : a Byesian Multitask Learning Aproach 1. MIS Quarterly, 41(2), 473495. 
[22] Wu, T., Wu, F., Redoute, J. M., \& Yuce, M. R. (2017). An Autonomous Wireless Body Area Network Implementation Towards IoT Connected Healthcare Applications. IEEE Access, 5, 11413-11422. DOI: https://doi.org/10.1109/ACCESS.2017.2716344.

[23] Knickerbocker, J., Budd, R., Dang, B., Chen, Q., Colgan, E., Hung, L. W., Wen, B. (2018). Heterogeneous integration technology demonstrations for future healthcare, IoT, and AI computing solutions. Proceedings - Electronic Components and Technology Conference, 2018May, 1519-1528. DOI: https://doi.org/10.1109/ECTC.2018.00231.

[24] Kodali, R. K., Swamy, G., \& Lakshmi, B. (2016). An implementation of IoT for healthcare. 2015 IEEE Recent Advances in Intelligent Computational Systems, RAICS 2015, (December), 411-416. DOI: https://doi.org/10.1109/RAICS.2015.7488451.

[25] Joyia, G. J., Liaqat, R. M., Farooq, A., \& Rehman, S. (2017). Internet of medical things (IOMT): Applications, benefits and future challenges in healthcare domain. Journal of Communications, 12(4), 240-247. DOI: https://doi.org/10.12720/jcm.12.4.240-247.

[26] Gandhi, D. A., \& Ghosal, M. (2018). Intelligent Healthcare Using IoT:A Extensive Survey. Proceedings of the International Conference on Inventive Communication and Computational Technologies, ICICCT 2018, (Icicct), 800-802. DOI: https://doi.org/10.1109/ICICCT.2018.8473026.

[27] Brown, S. J. (2010). (12) Patent Application Publication (10) Pub. No.: US 2008/0269571 A1. 1(19).

[28] Bui, N., \& Zorzi, M. (2011). Health care applications: A solution based on the Internet of Things. ACM International Conference Proceeding Series, 0-4. DOI: https://doi.org/10.1145/2093698.2093829.

[29] Darwish, A., Hassanien, A. E., Elhoseny, M., Sangaiah, A. K., \& Muhammad, K. (2019). The impact of the hybrid platform of internet of things and cloud computing on healthcare systems: opportunities, challenges, and open problems. Journal of Ambient Intelligence and Humanized Computing, 10(10), 4151-4166. DOI: https://doi.org/10.1007/s12652-017-06591.

[30] Das, A., Rad, P., Choo, K. K. R., Nouhi, B., Lish, J., \& Martel, J. (2019). Distributed machine learning cloud teleophthalmology IoT for predicting AMD disease progression. Future Generation Computer Systems, 93, 486-498. DOI:

https://doi.org/10.1016/j.future.2018.10.050.

[31] Datta, S. K., Bonnet, C., Gyrard, A., Ferreira Da Costa, R. P., \&Boudaoud, K. (2015). Applying Internet of Things for personalized healthcare in smart homes. 2015 24th Wireless and Optical Communication Conference, WOCC 2015, 164-169. DOI: https://doi.org/10.1109/ WOCC. 2015.7346198.

[32] Desai, P., Sheth, A., \& Anantharam, P. (2015). Semantic Gateway as a Service Architecture for IoT Interoperability. 2015 IEEE International Conference on Mobile Services. (pp. 313-319). IEEE. DOI: https://doi.org/10.1109/mobserv.2015.51.

[33] Deshpande, P. (2018). Predictive and prescriptive analytics in big data Era. Advances in Intelligent Systems and Computing, 810, 123132. DOI: https://doi.org/10.1007/978-981-131513-8 14.

[34] Dhanvijay, M. M., \& Patil, S. C. (2019). Internet of Things: A survey of enabling technologies in healthcare and its applications. Computer Networks, 153(March), 113-131. DOI: https://doi.org/ 10.1016/j.comnet.2019.03.006.

[35] Dohr, A., Modre-Opsrian, R., Drobics, M., Hayn, D., \& Schreier, G. (2010). The Internet of Things for Ambient Assisted Living. 2010 Seventh International Conference on Information Technology: New Generations. DOI: https://doi.org/110.1109/itng.2010.104.

[36] Dwivedi, A., Srivastava, G., Dhar, S., \& Singh, R. (2019). A Decentralized PrivacyPreserving Healthcare Blockchain for IoT. Sensors, $19(2), \quad 326 . \quad$ DOI: https://doi.org/10.3390/s19020326. 
[37] VijuRaghupathi, W. R. (2013). An Overview of Health Analytics. Journal of Health \& Medical Informatics, 04(03). DOI: https://doi.org/10.4172/2157-7420.1000132.

[38] Lubamba, C., \& Bagula, A. (2017). Cyberhealthcare cloud computing interoperability using the HL7-CDA standard. 2017 IEEE Symposium on Computers and Communications (ISCC). DOI: https://doi.org/10.1109/iscc.2017.8024513.

[39] Mahmud, R., Koch, F. L., \& Buyya, R. (2018). Cloud-Fog Interoperability in IoTenabled Healthcare Solutions. Proceedings of the 19th International Conference on Distributed Computing and Networking - ICDCN '18. DOI:https://doi.org/10.1145/3154273.3154347.

[40] Manogaran, G., Varatharajan, R., Lopez, D., Kumar, P. M., Sundarasekar, R., \& Thota, C. (2018). A new architecture of Internet of Things and big data ecosystem for secured smart healthcare monitoring and alerting system. Future Generation Computer Systems, 82, 375-387. DOI:

https://doi.org/10.1016/j.future.2017.10.045.

[41] Greco, L., Ritrovato, P., \& Xhafa, F. (2018). An edge-stream computing infrastructure for real-time analysis of wearable sensors data. Future Generation Computer Systems. DOI: https:// doi.org/10.1016/j.future.2018.10.058.

[42] Cruz, J. A., \&Wishart, D. S. (2006). Applications of machine learning in cancer prediction and prognosis. Cancer Informatics, 2, 59-77.

DOI: https://doi.org/10.1177/117693510600200030.

[43] Palani, D., \& Venkatalakshmi, K. (2018). An IoT Based Predictive Modelling for Predicting Lung Cancer Using Fuzzy Cluster Based Segmentation and Classification. Journal of Medical Systems, 43(2). DOI: https://doi.org/10.1007/s10916-018-1139-7.

[44] Pang, Z., Zheng, L., Tian, J., Kao-Walter, S., Dubrova, E., \& Chen, Q. (2013). Design of a terminal solution for integration of in-home health care devices and services towards the Internet-of-Things. Enterprise Information Systems, 9(1), 86-116. DOI: https://doi.org/:10.1080/17517575.2013.776118.

[45] Paschou, M., Sakkopoulos, E., Sourla, E., \& Tsakalidis, A. (2013). Health Internet of Things: Metrics and methods for efficient data transfer. Simulation Modelling Practice and Theory, 34, 186-199.

DOI: https://doi.org/10.1016/j.simpat.2012.08.002.

[46] Sharma, R., Gupta, S. K., Suhas, K. K., \& Kashyap, G. S. (2014). Performance Analysis of Zigbee Based Wireless Sensor Network for Remote Patient Monitoring. 2014 Fourth International Conference on Communication Systems and Network Technologies. DOI: https:// doi.org/10.1109/csnt.2014.21.

[47] Guntur, S. R., Gorrepati, R. R., \& Dirisala, V. R. (2019). Robotics in Healthcare: An Internet of Medical Robotic Things (IoMRT) Perspective. Machine Learning in Bio-Signal Analysis and Diagnostic Imaging, 293-318. DOI: https://doi.org/10.1016/b978-0-12-8160862.00012-6.

[48] Yoon, H. J. (2019). Blockchain technology and healthcare. Healthcare Informatics Research, 25(2), 59-60. DOI: https://doi.org/10.4258/hir.2019.25.2.59.

[49] Babu, B. S., Srikanth, K., Ramanjaneyulu, T., \& Narayana, I. L. (2016). IoT for Healthcare. International Journal of Science and Research (IJSR), 5(2), 322-326. DOI: https://doi.org/ $\underline{10.21275 / \mathrm{v} 5 \mathrm{i} 2 . n o v 161096 .}$

[50] Jingjing, Y., Shangfu, H., Xiao, Z., Benzhen, G., Yu, L., Beibei, D., \& Yun, L. (2015). Family health monitoring system based on the four sessions internet of things. Telkomnika (Telecommunication Computing Electronics and Control), 13(1), 314-320. DOI: https://doi.org/10.12928/ TELKOMNIKA.V13I1.1265.

[51] Kai, K.A.N.G., Pang, Z.B. \& Cong, W.A.N.G., (2013).Security and privacy mechanism for health internet of things. The Journal of China Universities of Posts and Telecommunications, 20, 64-68.

[52] Lotfy Abdrabou, E. A. M., \& Salem, A. M. (2010). A breast cancer classifier based on a 
combination of case-based reasoning and ontology approach. Proceedings of the International Multiconference on Computer Science and Information Technology. DOI: https://doi.org/10.1109/imcsit.2010.5680045.

[53] Harisekaran, S. S. D. G. (2015). Big Data Analytics Predicting Risk of Readmissions of Diabetic Patients. International Journal of Science and Research (IJSR), 4(4), 534-538. Retrieved from https://www.ijsr.net/archive/v4i4/SUB152923.p df.

[54] Sisodia, D., \& Sisodia, D. S. (2018). Prediction of Diabetes using Classification Algorithms. Procedia Computer Science, 132, 1578-1585.

DOI: https://doi.org/10.1016/j.procs.2018.05.122.

[55] Wu, T. H., Pang, G. K. H., \& Kwong, E. W. Y. (2014). Predicting systolic blood pressure using machine learning. 2014 7th International Conference on Information and Automation for Sustainability: "Sharpening the Future with Sustainable Technology”, ICIAfS 2014, 2014. DOI:

https://doi.org/10.1109/ICIAFS.2014.7069529.

[56] Koshimizu, H., Kojima, R., Kario, K., \& Okuno, Y. (2020). Prediction of blood pressure variability using deep neural networks. International Journal of Medical Informatics, 136, 104067. DOI : https://doi.org/10.1016/j.ijmedinf.2019.104067.

[57] Shamli, N., \& Sathiyabhama, B. (2016). Parkinson's Brain Disease Prediction Using Big Data Analytics. International Journal of Information Technology and Computer Science, 8(6), 73-84. DOI: https://doi.org/10.5815/ijitcs.2016.06.10.

[58] Sharma, G., \& Kalra, S. (2018). A Lightweight User Authentication Scheme for Cloud-IoT Based Healthcare Services. Iranian Journal of Science and Technology, Transactions of Electrical Engineering. DOI: https://doi.org/10.1007/s40998-018-0146-5.

[59] Arulanthu, P., \& Perumal, E. (2020). An intelligent IoT with cloud centric medical decision support system for chronic kidney disease prediction. International Journal of Imaging Systems and Technology. DOI: https://doi.org/10.1002/ima.22424.

[60] Ram, S., Zhang, W., Williams, M., \& Pengetnze, Y. (2015). Predicting Asthma-Related Emergency Department Visits Using Big Data. IEEE Journal of Biomedical and Health Informatics, 19(4), 1216-1223. DOI:https://doi.org/10.1109/JBHI.2015.2404829

[61] Chatterjee, P., Cymberknop, L. J., \& Armentano, R. L. (2017). IoT-based decision support system for intelligent healthcare applied to cardiovascular diseases. 2017 7th International Conference on Communication Systems and Network Technologies (CSNT). DOI: https://doi.org/10.1109/ csnt.2017.8418567.

[62] Patel, A. R., Patel, R. S., Singh, N. M., \& Kazi, F. S. (2017). Vitality of Robotics in Healthcare Industry: An Internet of Things (IoT) Perspective. Internet of Things and Big Data Technologies for Next Generation Healthcare, 91-109. DOI: https://doi.org/10.1007/978-3319-49736-5 5.

[63] Sundaravadivel, P., Kesavan, K., Kesavan, L., Mohanty, S. P., Kougianos, E., \& Ganapathiraju, M. (2018). Smart-log: An automated, predictive nutrition monitoring system for infants through the IoT. 2018 IEEE International Conference on Consumer Electronics, ICCE 2018, 2018-January, 1-4. DOI:

https://doi.org/10.1109/ICCE.2018.8326068.

[64] Yilmaz, T., Foster, R., \& Hao, Y. (2010). Detecting Vital Signs with Wearable Wireless Sensors. Sensors, 10(12), 10837-10862. DOI: https://doi.org/10.3390/s101210837.

[65] Ullah, F., Habib, M. A., Farhan, M., Khalid, S., Durrani, M. Y., \& Jabbar, S. (2017). Semantic interoperability for big-data in heterogeneous IoT infrastructure for healthcare. Sustainable Cities and Society, 34, 90-96. DOI: https://doi.org/10.1016/j.scs.2017.06.010.

[66] Chen, Y., Hao, H. W., Hu, Y. X., \& Li, L. M. (2013). Wireless wrist-wearable wake/sleep 
identification device for closed-loop deep brain stimulation. Electronics Letters, 49(7), 497-499. DOI: https://doi.org/10.1049/el.2013.0382.

[67] Park, J., Kim, J., Kim, S.-Y., Cheong, W. H., Jang, J., Park, Y.-G., ... Park, J.-U. (2018). Soft, smart contact lenses with integrations of wireless circuits, glucose sensors, and displays. Science Advances, 4(1), eaap9841.DOI:https://doi.org/10.1126/sciadv.aa p9841.

[68] Tarouco, L. M. R., Bertholdo, L. M., Granville, L. Z., Arbiza, L. M. R., Carbone, F., Marotta, M., \& de Santanna, J. J. C. (2012). Internet of Things in healthcare: Interoperatibility and security issues. 2012 IEEE International Conference on Communications (ICC), 6121-6125, DOI: https://doi.org/ 10.1109/icc.2012.6364830.

[69] Islam, S. M. R., Kwak, D., Kabir, M. H., Hossain, M., \& Kwak, K. S. (2015). The internet of things for health care: A comprehensive survey. IEEE Access, 3, 678-708. DOI: https://doi.org/

\subsection{9/ACCESS.2015.2437951.}

[70] Li, Y., Chen, F., Sun, Z., Weng, Z., Tang, X., Jiang, H., \& Wang, Z. (2017). System architecture of a smart binaural hearing aid using a mobile computing platform. 2017 IEEE 12th International Conference on ASIC (ASICON), 440-443, DOI: https://doi.org/10.1109/asicon.2017.8252508.

[71] Ray, P. P., Dash, D., \& De, D. (2017). A Systematic Review of Wearable Systems for Cancer Detection: Current State and Challenges. Journal of Medical Systems, 41(11), 1-12, DOI: https:// doi.org/10.1007/s10916-017-0828-y.

[72] Spano, E., Di Pascoli, S., \& Iannaccone, G. (2016). Low-Power Wearable ECG Monitoring System for Multiple-Patient Remote Monitoring. IEEE Sensors Journal, 16(13), 5452-5462.DOI: https:// doi.org/10.1109/jsen.2016.2564995.

[73] Ianculescu, M., Alexandru, A., Coardoa, D., \& Coman, O. A. (2018). General Reports Smart Wearable Medical Devices - The Next Step in Providing Affordable Support for Dermatology Practice. (Ici), 41-46.
[74] Kalantar-zadeh, K., Ha, N., Ou, J. Z., \& Berean, K. J. (2017). Ingestible Sensors. ACS Sensors, 2(4), 468-483. DOI: https://doi.org/10.1021/acssensors.7b00045.

[75] Karakra, A., Fontanili, F., Lamine, E., \& Lamothe, J. (2019). HospiT'Win: A predictive simulation-based digital twin for patients pathways in hospital. 2019 IEEE EMBS International Conference on Biomedical and Health Informatics, BHI 2019 - Proceedings, 14. DOI: https:// doi.org/10.1109/BHI.2019.8834534.

[76] Lee, U., Han, K., Cho, H., Chung, K.-M., Hong, H., Lee, S.-J., Carroll, J. M. (2019). Intelligent positive computing with mobile, wearable, and IoT devices: Literature review and research directions. Ad Hoc Networks, 83, 8-24. DIO: doi.org/10.1016/j.adhoc.2018.08.021.

https://

[77] Alharthi, H. (2018). Healthcare predictive analytics: An overview with a focus on Saudi Arabia. Journal of Infection and Public Health, 11(6), 749-756.

https://doi.org/10.1016/j.jiph.2018.02.005.

[78] Ed-Daoudy, A., \& Maalmi, K. (2019). Realtime machine learning for early detection of heart disease using big data approach. 2019 International Conference on Wireless Technologies, Embedded and Intelligent Systems (WITS). DOI: https:// doi.org/10.1109/wits.2019.8723839.

[79] Kamel, M., Fawzy, S., El-Bialy, A., \& Kandil, A. (2011). Secure remote patient monitoring system. 2011 1st Middle East Conference on Biomedical Engineering. DOI: https://doi.org/10.1109/mecbme.2011.5752135.

[80] Khanna RC, Cicinelli MV, Gilbert SS, Honavar SG, Murthy GS. (2020) COVID-19 pandemic: Lessons learned and future directions. Indian Journal of Ophthalmology, 68(5), 703. DOI: https:// doi.org/10.4103/ijo.IJO-843-20 .

[81] Kang, M., Park, E., Cho, B. H., \& Lee, K. S. (2018). Recent patient health monitoring platforms incorporating Internet of Thingsenabled smart devices. International 
Neurourology Journal, 22(Suppl 2), S76-S82.

$* * * * * * * * * * * * * * * * *$

DOI: https://doi.org/10.5213/inj.1836144.072.

[82] Thompson, A., Brennan, K., Cox, A., Gee, J., Harcourt, D., Harris, A., Streuli, C. (2008). Evaluation of the current knowledge limitations in breast cancer research: A gap analysis. Breast Cancer Research, 10(2), 1-25. DOI: https://doi.org/10.1186/bcr1983.

[83] Guazelli, A. (2011). Predictive analytics in healthcare. Intel White Paper - Solution Brief, 17.

DOI:

https://doi.org/10.1017/CBO9781107415324.00

$\underline{4 .}$ 